THE BLONDE SALAD: A CASE STUDY OF THE DEMOCRATIC POTENTIAL OF FASHION BLOGGING IN A NEW MEDIA ENVIRONMENT

by

Rachel Mostert

BA, McMaster University, 2015

\author{
An MRP \\ presented to Ryerson University \\ in partial fulfillment of the \\ requirements for the degree of \\ Master of Arts \\ In the Program of \\ Fashion
}

Toronto, Ontario, Canada, 2017

CRachel Mostert, 2017 
AUTHOR'S DECLARATION FOR ELECTRONIC SUBMISSION OF AN MRP

I hereby declare that I am the sole author of this MRP. This is a true copy of the MRP, including any required final revisions.

I authorize Ryerson University to lend this MRP to other institutions or individuals for the purpose of scholarly research.

I further authorize Ryerson University to reproduce this MRP by photocopying or by other means, in total or in part, at the request of other institutions or individuals for the purpose of scholarly research.

I understand that my MRP may be made electronically available to the public. 


\title{
THE BLONDE SALAD: A CASE STUDY OF THE DEMOCRATIC POTENTIAL OF FASHION BLOGGING IN A NEW MEDIA ENVIRONMENT
}

\author{
Rachel Mostert \\ Master of Arts in Fashion \\ Ryerson University, 2017
}

\begin{abstract}
This Major Research Project examines the ways in which the trust that consumers have in fashion blogging as a form of user-generated fashion media may aid in the reproduction of conventional fashion hierarchies. Where consumers may assume that all blog content is created by bloggers themselves, other influences (from fashion "experts" and established brands) often play a large role in dictating content for bloggers. This research questions whether fashion blogging has the potential to create a more open and democratic fashion market. To illustrate these ideas, the project engages in an in-depth case study of one popular fashion blogger, Chiara Ferragni and her blog, The Blonde Salad. Using a theoretical analysis based on concepts of capital discussed by Pierre Bourdieu, this research uses The Blonde Salad blog as an example to demonstrate the influences at play within the making of popular fashion blog content and to question power relations at play within the fashion blogosphere.
\end{abstract}




\section{ACKNOWLEDGEMENTS}

I would like to express my utmost gratitude to everyone that supported me throughout the writing of this paper. I am so thankful for the countless instances of aspiring guidance, constructive criticism, and friendly advice that I received during my project work. I have dedicated much time and effort into this project, but it would not have been possible without the guidance and support of the following people.

To begin, I would like to thank my dedicated Supervisor, Program Director, and friend, Dr. Alison Matthews David. This paper owes much to your scholarly insights and invaluable advice. Thank you for taking such an interest in this topic of research and for your constant willingness to motivate my research to be taken further. This project would not have been the same without your guidance. I would like to thank my second reader, Louis Weinthal, for her continued support and discernment of my work. In addition, I would like to thank all of my professors and peers within the MA Fashion program at Ryerson. I found myself consistently learning from each and every one of you and I am continuously inspired by your own research endeavors. Particularly, I would like to thank Antonietta, Dan, Erin, Gabby, Sam, and Shelley; you started as my classmates and quickly became some of my most treasured friends and supporters. Your friendship motivated me throughout my research and I am so thankful to have worked alongside such talented and intelligent individuals in the pursuit of this degree. Finally, this research would not have been possible without the loving support of my family and friends. Thank you to my parents and brother for continuing to be so patient, understanding, and encouraging throughout the entirety of my academic career. For that I am eternally grateful. Lastly, I would like to thank my boyfriend, Robert, for continuing to be a source of serenity throughout the course of this degree. My work and life has been greatly enriched these past two years from your support and I would not be able to present this research today without all of you. 


\section{TABLE OF CONTENTS}

1. INTRODUCTION

$\begin{array}{ll}\text { 2. REView OF RELEVANT Literature } & 7\end{array}$

The Influence of Bloggers within the Fashion Industry 7

The Democratic Potential of New Media Forms 9

Contemporary Fashion Tastemakers and Relations of Power 16

The Perceived Authenticity of Fashion Blogging 19

Blog Professionalization, Brand Collaboration, and Mutually Beneficial Relationships 21

3. Methodology AND THEORETiCAL FRAMEWORK 26

Pierre Bourdieu: Habitus, Field Theory, and Capital 26

The Field of Fashion $\quad 31$

Bourdieu and Fashion Blogging $\quad 32$

The Blonde Salad Blog Case Study and Analysis 33

Anticipated Outcomes and Contributions

4. ANAlysis AND Discussion 36

The Blonde Salad: An Introduction to my Case Study 36

Posts for Analysis

"Here I Am!" (12 October 2009) 40

"After the Cinema" (14 October 2009) 42

"Milano by Night" (23 October 2009) 45

"Wearing Miu Miu” (28 May 2010) 46

"My First Day of Paris Fashion Week" (4 March 2011) 48

"Electric Blue Jeans + Cream Sweater" (26 October 2011) 51

"Show Your Potential" (24 May 2012) 52

"Miami Day 3" (20 December 2013) 55

"California House" (16 October 2014) 56

"Chiara Ferragni S/S 2015 Campaign" (15 January 2015) 57

"Sunset Lights in Paris" (6 July 2016) 59

"Let's Get Minimal” (8 March 2017)

Concluding Case Study Discussion: The Blonde Salad Blog Progression 61

$\begin{array}{ll}\text { 5. CONCLUSION } & 67\end{array}$

$\begin{array}{ll}\text { WORKS CITED } & 72\end{array}$ 


\section{LIST OF FIGURES}

Figure 1: "Here I Am!” The Blonde Salad's first post 40

Figure 2: "After the Cinema" Ferragni and friend, Angie 42

Figure 3: "After the Cinema" Ferragni alone in a square in Milano 43

Figure 4: "Milano by Night" Ferragni in Milano 45

Figure 5: "Wearing Miu Miu” Ferragni in Miu Miu shoes/collar and Chanel bag 47

Figure 6: "My First Day of Paris Fashion Week" Ferragni walking the streets of Paris Fashion

Week 2011

Figure 7: "My First Day of Paris Fashion Week" Ferragni wearing her own shoe collection being photographed in Paris 49

Figure 8: "Electric Blue Jeans + Cream Sweater"

Figure 9: "Electric Blue Jeans + Cream Sweater" Indication of Gifted Merchandise for $\begin{array}{ll}\text { Ferragni } & 51\end{array}$

Figure 10: "Show Your Potential" Ferragni gives her readers life tips 53

Figure 11: "Miami Day 3" 56

Figure 12: "California House"

Figure 13: "Chiara Ferragni S/S 2015 Campaign" Ferragni uses a shoe that she designed as a prop $\quad 57$

Figure 14: "Chiara Ferragni S/S 2015 Campaign” 58

Figure 15: "Sunset Lights in Paris"

Figure 16: "Let's Get Minimal” $\quad 60$ 


\section{INTRODUCTION}

Fashion blogging as a form of fashion media has gained significant popularity in recent years. Many consumers turn to fashion blogs for advice and inspiration regarding the latest fashion trends, styles, and brands, just as they used to exclusively turn to fashion magazines and editorials. In recent years, the increasing popularity and widespread acceptance of personal style blogs as reliable sources of fashion knowledge for consumers has led to the tendency for style bloggers to pursue the commercialization of their blogs. In such cases, bloggers seek monetary gain from the upkeep of their blog and often adopt the blog as a full time job if they have a strong enough readership base. My research explores the potential that fashion blogs have to revolutionize the field of fashion, but also brings to light potential illusions that optimistic ideas regarding the democratic potential of fashion blogs create.

Rocamora ("Personal Fashion Blogs") discusses the increasing prevalence of fashion bloggers as actors within the fashion industry (408). She provides a brief explanation of what blogs actually are in which she asserts that, "the term blog comes from the contraction of the words 'web' and 'log'” and that, "blogs are Internet sites on which individuals regularly publish their thoughts on a particular subject. The texts - called posts - appear ante-chronologically and are usually accompanied by images, and, sometimes, videos and music" (408). Rocamora ("Personal Fashion Blogs") goes on to state that over two million bloggers were listed as under the heading of fashion in July 2010 and we can assume that this number has increased significantly over the past seven years (409). Within the blogging genre, there are independent blogs and corporate blogs (409). Independent blogs are "usually run by one individual only, as opposed to corporate blogs, which are the voice of a fashion institution" (409). This research focuses on personal style blogs, which Rocamora ("Personal Fashion Blogs") defines as, "those blogs whose authors post pictures of themselves to document their outfit on a regular basis," but 
also delves into some analysis of corporate brand blogging in my analysis of The Blonde Salad blog through the trajectory that the blog takes from personal style blog to corporate blog and online lifestyle magazine (409).

Jacobs suggests that where traditional forms of fashion media, like fashion magazines, dictated trends for women, in reality, the contemporary woman "has not wanted to be told what to wear in some time" (2). Blogging allows for consumers to take inspiration from seemingly ordinary tastemakers that create outfit posts because they want to express personal style rather than prescribe new trends for the season. Crewe also suggests that, "consumers are relying less on the authority of conventional branding and advertising campaigns for their consumption knowledge" (770). She proposes that, "digital developments have given voice, knowledge, and power to larger and more diverse consumer groups, many of whom lacked any sense of authority or persuasion under the conventional hierarchical fashion system with its high barriers to entry and exclusionary practices" (770). In this way, "the balance of power between fashion producers/intermediaries and consumers in terms of who shapes brand perception, and fashion knowledge appears to be shifting" (770). Like Crewe, Pham ("Blog Ambition") suggests that, "in 2009, the fashion press declared it the Year of the Fashion Blogger" (27). She mentions that both online and print media publications were saturated with articles about fashion bloggers with titles like, “'Style Bloggers Bring Fashion to the Masses'; 'Social Media + Blogger $=$ The Democratization of Fashion'; and 'Bloggers Crash Fashion's Front Row”" (27). The widespread attention that fashion blogging has received as a democratic fashion alternative is therefore one worthy of academic attention.

The widespread belief that fashion blogging is a more democratic and participatory way to disseminate fashion knowledge stems from the opportunity that fashion blogging gives regular 
consumers to create their own fashion media content for an audience to see. Anyone with access to the internet can start a blog, therefore allowing a much larger variety of people to offer up opinions in a discussion that was previously segregated to so-called fashion 'experts' and professional gatekeepers, including fashion magazine editors, fashion house designers/creative directors, and socialites. While this positive outcome is possible and these optimistic ideas are valid, they do not account for the small number of fashion blogs that actually gain mass audiences and readership. These select few blogs (such as the Blonde Salad, The Fashion Guitar, Fashion Toast, Style Bubble, etc.) and their authors are the ones that have influence within the larger field of fashion, making these bloggers new fashion 'experts'. With this popularity and authority comes many new influences that contribute to greater success on the part of these bloggers, which then leads to questions regarding the authenticity of the blog itself; how much of the blog's content is actually user-generated without external influence from previously mentioned fashion experts and brands? Research by many prominent theorists within the field such as Rocamora, Pham, and McQuarrie et al., suggests that fashion blogs are a more trusted form of fashion media because they are created by non-professionals and their content is usergenerated. In recent years, there has been a shift within fashion blogging to include increasingly less content that is created/influenced only by the blog author; instead, much blog content is authored and influenced by external forces (fashion 'experts' and brands), creating the need for new research to explore these changes. My research calls into question the legitimacy of the optimistic assumptions surrounding the authenticity and democratic potential of fashion blogging and illuminates power relations that have been masked by these hopeful ideas.

Entwistle argues that within the recent fashion industry, fashion tastemakers such as designers, buyers, and editors have realized that although "an elite [fashion tastemaker] may 
influence the direction of taste, ...they do not control it and attempts made to co-ordinate popular taste can fail" (222). Consumers are increasingly taking influence from street trends and new media forms, like blogging. The "trickle down" effect within the fashion market is losing validity; fashion elites must work to find a new and more effective way of influencing the market (Entwistle 221). This is where new cultural intermediaries like fashion bloggers play a role. Importantly, Entwistle suggests that:

These developments have served to blur the division between high fashion and everyday fashion; the latter hardly lags behind 'high' fashion and in many cases dictates the trends that are only later picked up by couture [sic]. With new sources of fashion coming up from the street, the orderly dissemination of high fashion from couture collections each season is no longer viable. (223)

Further, Rouse argues that in order for "“a particular style of clothing to become fashion it actually has to be worn by some people and recognized and acknowledged to be fashion"' (qtd. in Entwistle 48). Cultural intermediaries, like fashion bloggers, today act as testimonials for major fashion brands, assuring consumers that certain styles are fashionable and dictating trends for the season. Although the ability to start a blog is possible for regular fashion consumers, Entwistle states that "styles are always mediated by other social factors, such as class, gender, ethnicity, age, occupation, income and body shape, to name but a few" (49). In an analysis of the democratic potential of fashion blogs within the industry, it is important to acknowledge these influences when investigating power relations at play in fashion blog success.

My Major Research Project examines the ways in which the trust that consumers have in fashion blogging as a form of user-generated fashion media may aid in the reproduction of conventional fashion hierarchies that are dictated by the pursuit of capital. Where consumers 
may assume that all blog content is created by bloggers themselves, other influences often play a large role in dictating content for bloggers, which they often engage with to monetize their blog and increase their own production of different forms of capital. Further, blogs may reproduce problematic 'norms' that have been and are advocated by traditional fashion media forms, which include the perpetuation of a certain body type, beauty ideal, and overall a particular definition of what should be considered fashionable or beautiful within Western culture. My research explores the influences at play within the making of popular fashion blog content. It also questions power relations at play within the fashion blogosphere.

Some questions that my research addresses are: Does fashion blogging have the potential to create a more open and democratic or inclusive fashion market? Or does fashion blogging in fact reproduce existing beauty norms and ideals through the deception of consumers, who assume that gaining influence within the field of fashion is open to regular consumers? What factors contribute to the success of a fashion blogger and why? Whose voice actually has the potential to be heard? Finally, what happens to a fashion blogger after their commercial success? What factors exist to influence further success from this point on? These factors may include bloggers' roles in advertising, attendance at fashion weeks around the world, gifted merchandise from fashion houses and brands, and blogger-brand collaborations. This project attempts to bring to light any misconceptions that the field of fashion blogging has created for consumers and to make explicitly visible the power relations at play within the creation and dissemination of fashion blogs. It also seeks to inspire and encourage the success of alternative fashion bloggers and entirely independent fashion blogs in the future.

This project draws on the fields of New Media and Communications, Sociology, Cultural Studies, and Fashion Studies to mobilize knowledge that will be relevant to both scholars and 
actors within the fashion industry. In particular, this research is important because of the enormous influence that fashion blogging now has within the fashion industry. For example, my case study analysis focuses on the Blonde Salad blog, the world's most popular fashion blog according to Indvik, a writer for online fashion publication Fashionista. The Blonde Salad blog has today become its own brand as well as online lifestyle magazine. Its founder, Chiara Ferragni, has enormous influence within the industry and acts as a key influencer within the luxury fashion market. Fashion research that will be conducted in the future will draw on the influence of fashion blogging as a form of fashion media and this research project will serve as a resource in a growing body of scholarly literature surrounding the potential that new media forms like blogs have to revolutionize the fashion industry. Importantly, the popularity of the fashion blog has led academics to argue for a fundamental re-theorization of the relationship between the production and consumption of fashion knowledge among consumers; my research examines the fashion blog through the lens of democracy and participatory potential for consumers within the fashion industry and serves as a stepping-stone for further research and theorization. 


\section{REVIEW OF RELEVANT LITERATURE}

\section{The Influence of Bloggers within the Fashion Industry}

Many prominent theorists have argued for the continually increasing influence that blogs have within the fashion industry and within the media more generally (Crewe, Rocamora, Pham, McQuarrie et al., Engholm and Hansen-Hansen, Sedeke and Arora, Matthews). A study by PEW Internet and American Life Project has concluded that blogging has welcomed new voices into the online media world that were not heard before (Lenhart and Fox 2). The study was completed over a decade ago in 2006, so a more recent study would yield more current results, but this research provides some context and background information on blogging. The study found that around eight percent of Internet users (or around twelve million American adults) kept a blog while thirty-nine percent (or around fifty-seven million American adults) engaged in reading blogs (Lenhart and Fox 2). The study's findings also concluded that most bloggers were young (under thirty years old) and were only about sixty percent white, which is actually less than the general population, making bloggers less likely to be white than usual (3). The PEW study also found that the most popular blog topic among participants was bloggers' own life and experiences and most bloggers listed the main reason that they kept a blog as "creative expression" (4). Importantly, the vast majority of bloggers in the study were avid consumers and creators of online content (4). This research demonstrates the participatory nature of blogging as well as the popular utilization of the blog platform to give voice to people from a wide range of backgrounds.

Just as blogging has become an increasingly influential tool in everyday life, it has also gained significant influence within the field of fashion in recent years. Agnes Rocamora ("Personal Fashion Blogs") states that there were around two million bloggers in the year 2010 listed within the fashion industry (409). She asserts that the blogosphere has quickly grown to 
become a key platform in the "production and circulation of fashion discourse" (409). Louise Crewe argues that since the rise of new media forms, the material and virtual fashion worlds are eternally intersecting social realities (760). Engholm and Hansen-Hansen suggest that the advent of digital media in the 2000s created new ways of communicating and presenting fashion (140). Particularly with the rise in popularity of digital media, though, the blog played one of the most important roles in creating a new form of media culture through fashionable self-presentation (140). Pham ("Blog Ambition") argues that even though the number of fashion-themed bloggers is small in comparison to other blog forms, their influence is unquestionable (11). This influence is evidenced through "the growing incorporation of bloggers into various sectors of the fashion industry" (Pham 11). For example, many fashion bloggers are now accredited as fashion journalists, are used as editorial subjects, photographers, and writers in fashion magazines, as well as unofficial brand promoters and trend forecasters (11). Pham also mentions that even some designers, such as Marc Jacobs and Rodarte, have welcomed bloggers as muses for their work (11). Meyers argues that although most bloggers do not have professional experience or affiliation within their respective industries, they are carving a niche within the industry, which operates outside of conventional media rules (1029). As a whole, fashion bloggers have been received into the fashion industry as leading influencers.

Engholm and Hansen-Hansen suggest that the fashion blog as a genre brought about "new ways of communicating and staging fashion" (140). Rocamora ("Hypertextuality and Remediation") goes as far as to suggest that fashion blogs have completely changed the way that fashion is looked at through changes in "production, circulation, and consumption of fashion discourse" (93). She argues that remediation has occurred as "a two-way process: new media borrow and refashion old media, which in turn refashion new media to absorb some of their 
characteristics in their pages" (103). In this way, new media forms, blogs in particular, work in codependence with old media forms rather than in direct competition (104). Bloggers borrow from print media regularly, just as print media is beginning to shift to incorporate some aspects of blogging as well. Matthews conversely discusses changes in the fashion industry in terms of the "variety of voices that compete for attention," arguing that fashion bloggers' voices are increasingly heard and respected (53). She suggests that recently, the fashion media environment has developed a taste for "infotainment" in which fashion knowledge is expressed in a way that is also some form of entertainment (53). Blogs are the perfect platform for this newly invited form of media dissemination. Matthews's research describes fashion bloggers as important tastemakers in the industry today, using personal contemporary communication channels such as social media to "extend their sphere of influence" (54). An important change in the way that fashion knowledge is disseminated is expressed through suggestion rather than dictation; fashion bloggers use their influence and trusted status to lead by style example rather than expressively dictate trends of the season, making the consumer less and less passive in the creation of fashion knowledge (Matthews 54).

\section{The Democratic Potential of New Media Forms}

Important to a discussion such as this one is a clear understanding of the term 'democracy' in the context of this research. Predominantly, this understanding is based on power relations, particularly in terms of media relationships. Dick Hebdige provides a useful book on the topic of power hierarchies in the media. He suggests that, "access to the means by which ideas are disseminated in our society (i.e. principally the mass media) is not the same for all classes. Some groups have more say, more opportunity to make the rules, to organize meaning, while others are less favourably placed, have less power to produce and impose their definitions 
of the world on the world" (14). Drawing on the work of Marx and Engels (1970), Hebdige states that the media is largely representative of ruling class ideals and tends to ignore working class interests (15). Mass media propagates particular ideologies that are "by no means neutral," resulting in a fairly unrepresentative media system for the general population (15). Hebdige references Marx and Engels in which they argue that, "the class which has the means of material production at its disposal, has control at the same time over the means of mental production, so that generally speaking, the ideas of those who lack the means of mental production are subject to it" (15). Based on Hebdige's work, then, we can conclude that traditional forms of media dissemination like television and radio are biased toward the needs of the ruling class, therefore the dominant ideology that is professed to the general public does not often take into account the plight of the working class.

Definitions of democracy that are relevant to this discussion stem from this conflation of media and power. Pratchett discusses the concept of democracy as, "“a form of government in which, in contradistinction to monarchies and aristocracies, the people rule"' (Held qtd. in Pratchett 616). Important to this definition is the centrality of public participation and input on issues and discussions that involve citizens. Conventional media sources often do not involve the general public in discussions of popular issues, therefore indicating a less than democratic dissemination system. Pratchett argues that "democratic practice is influenced by enhanced participation," implying that the more public participation takes place, the more representatively democratic the system (616). Vatikiotis adds to this definition of democracy by discussing the "fundamental approaches of the democratic process, drawing on the aspects of engagement, participation and agency" (294). Again, participation is listed as a key aspect of democratic 
practice. He does, however, list democracy as a regularly contested term, particularly in regard to the potential of new media forms (294).

The rise of new media has sparked discussions about the democratizing potential of the Internet, which has allowed for greater public participation and open discussion. Alasuutari, Luomanen, and Peteri suggest that, "the computer has evolved into a generic tool and a link to the world at large" (459). Connell proposes that "the Internet is, by its very nature, a form of participatory culture," but does this idea indicate democracy (210)? Importantly, since new media forms like the Internet gained popularity, everyday people are becoming more and more selective about the media they engage with, largely due to the fact that they have wider access to information (Alasuutari et al. 457). Along with the rise of new media came the rise of social media. Loader and Mercea discuss social media as being more "open and collaborative" for networking than any other form of media (757). The citizen has been given the opportunity to be heard, allowing for the potential of greater participatory democracy to take place (Loader and Mercea 758). Loader and Mercea argue that in light of social media's popularity, "citizens no longer have to be passive consumers... but are instead actually enabled to challenge discourses, share alternative perspectives and publish their own opinions" (759). Friedland goes as far as to suggest that new technologies have completely changed the concept of democracy, allowing for the potential of consumers to be active authors of media content (185). The potential for increased democracy as a result of new media is real, but not all discussions of new media point to this optimistic conclusion.

Several theorists have outlined the negative aspects and limitations of new media's form of networked democracy (Friedland, Vatikiotis, Cover, Loader and Mercea). Cover acknowledges the potential for increased public participation that new digital technologies allow 
for, but he also suggests that, "various constraints and controls... are sometimes put in place to constrain the levels of participation and maintain narrative control" (173-74). Loader and Mercea reference Hill and Hughes, who argue that new media is "more likely to be shaped by the existing entrenched social and economic interests of contemporary societies" (758). Friedland argues that along with increased public participation comes increased opportunity for electronic surveillance (185). Vatikiotis touches on the transformative potential that blogging has as a form of journalism, allowing citizen journalists to contribute information and potentially disrupting traditional media hierarchies (297), but he also draws attention to some of the problems surrounding citizen journalism. Unequal levels of technological literacy, unclear lines between professional and amateur journalists, limited validity of amateur journalists' work, increased surveillance, and commercial appropriation are just a few threats to the democratizing potential of new media forms (298). Many theorists do, however, discuss the opportunity that blogging provides ordinary people with no professional backgrounds to participate in and contribute to the production of knowledge, particularly within the field of fashion (Vatikiotis, Scaraboto and Fischer, McQuarrie et al., Rocamora, Engholm and Hansen-Hansen, Meyers, Pham, Crewe).

Rocamora ("Personal Fashion Blogs") suggests that the rapid growth in the popularity of blogging can be mainly attributed to the two-way communication potential that blogs provide users with (408). Crewe openly discusses the need for a "retheorization of the agentive capacity of consumers and their abilities to disintermediate existing industry hierarchies and to create and reproduce fashion knowledge and markets" (761). She goes further to suggest that increased consumer participation within the field of fashion creates a strong possibility for a "more open, transparent, and democratic fashion system" (761). Crewe also argues that producers and consumers of fashion knowledge are becoming more closely aligned in terms of knowledge, 
power, and authority and that it can be argued that digital fashion developments have allowed for larger and more diverse groups of people to have voice, knowledge and power within the fashion industry (770). Meyers argues that bloggers play a unique part in the media system because they have the potential to act as mouthpieces for minority and unheard groups in the mainstream media (1036). Comparably, Connell suggests that the medium of the Internet has allowed for 'the increased ability of former fashion 'outsiders' to participate in the production of fashion discourse" (210). This argument is echoed in other research conducted by Rocamora, Pham, Connell, Scaraboto and Fischer, Loader and Mercea, Crewe, and Fink and Miller.

Rocamora ("Personal Fashion Blogs") argues that "fashion blogs have also enabled women traditionally excluded from the realm of fashion imageries to enter its visual scape" (421). Pham ("I Click and Post and Breathe") also argues that participatory media technologies "enable people whose images are invisible or are distorted in traditional media to capture and direct attention to non-normative bodies and identity presentations" (233). Rocamora ("Personal Fashion Blogs"), Pham (“Blog Ambition”, “Archival Intimacies”, "I Click and Post and Breathe"), and Crewe all discuss the fashion blog as a conceivable site of resistance to conventional hegemonic norms perpetuated by the fashion industry. Several case studies illustrating this potential stand out. Fink and Miller published a study on Trans Tumblr blogs in which they discuss the opportunity that the Tumblr blog platform has provided for selfrepresentation in a culture that has historically "co-opted, oversimplified, fetishized, and erased" trans people's concerns in "mainstream media outlets and cultural productions" (615). Similarly, Scaraboto and Fischer conducted a study on the "fa(t)shion blogging" community, concluding that many plus-sized "fatshionistas" turned to blogging to express their frustration at the lack of representation in the fashion industry of plus-sized women and clothing (1239). They suggest 
that while the fashion industry has largely been prejudiced against fat, these bloggers were able to create a space in which plus-sized fashion consumers were welcomed and celebrated (1239). Connell's research explains the "Fa(t)shion February," a movement that debuted on the Sociological Images blog as a form of research into the potential that minoritized groups in the industry have to resist hegemonic discourses (221). She finds that, "Fa(t)shion February challenges boundaries about who may legitimately participate in fashion as a cultural practice and subverts traditional notions of how this participation takes form" (217), suggesting that the blogging platform has the potential to be "a site of liberation and resistance" (221). Pham (“Archival Intimacies”) discusses her own blog, Of Another Fashion, as a site of resistance for women of colour to include their own representations of themselves in historical fashion knowledge (114). She argues that the blog provides an "oppositional memory of not only fashion and style but also an opposing viewpoint of the lived experiences of US women of colour with respect to fashion" (109).

Another way that both Rocamora ("Personal Fashion Blogs") and Pham ("I Click and Post and Breathe") discuss the representational possibility that fashion blogging provides is through the agency that is enacted when women post representations of themselves online. These images are for women and by women, which stands in opposition to the way that women are most commonly represented within the fashion industry as objects of the male gaze. Rocamora ("Personal Fashion Blogs") discusses the idea that the power relations between men and women in Western society heavily influence traditional fashion images. She argues that, "the former have generally been in command of the production of images, thereby creating a visual field wherein the latter have been positioned as objects of the masculine gaze" (415). Importantly, Rocamora ("Personal Fashion Blogs") argues that personal fashion blogs allow women to have 
"operational power in their own portraiture and the full independence, creativity, and control this power enables" (419). In this way, bloggers become both content producers and subjects. Pham's ("I Click and Post and Breathe") work outlines that bloggers are able to choose what style photo they want to take, where to position their body parts in relation to the camera, which blog platform to use, what HTML tags and hashtags to use, what types of photo editing to do, as well as when and if the image is posted online (224). She argues that, "participatory media allows the networked subject-as-represented object a hand in shaping and controlling their representation" (224). Significantly, these arguments suggest that (predominantly female) fashion bloggers gain social power by taking control of their own representation in the fashion industry. Pham ("I Click and Post and Breathe") also discusses the phenomenon of the selfie, arguing that it can be viewed as "a do-it-yourself technique of visibility" in which those conventionally rendered invisible in fashion media become visible in a way that is determined by them (231).

Unfortunately, though, not all research on the democratic potential of fashion blogging yields positive results. The limits to democracy previously discussed with regard to new media technologies apply to the fashion blogosphere as well. In addition to these limitations surrounding new media, fashion blogging brings about its own limitations in establishing democracy within the fashion industry. Rocamora ("Hypertextuality and Remediation") argues that because electronic media like blogging has the potential to be constantly updated, blogs have a short memory. In this way, the constant stream of new posts that fashion blogs provide "feed into this tyranny of the new, constructing, more than any other media, fashion as transient, passing, already gone" (97). A new fashion post on a blog can be posted and shared in seconds and, unlike traditional media sources, electronic media posts can point the consumer directly to the merchandiser where the items featured can be purchased in one click (98). In this way, 
fashion blogging may perpetuate and reinforce a fashion culture of constant consumption and, in turn, further capitalist interests. As Crewe puts it, digitally mediated fashion can be looked at as "an additional space for the production of desire" (765). Rocamora ("Personal Fashion Blogs") also argues that in some ways, fashion blogging acts as a way for women to objectify themselves and put their bodies on display for the male gaze (415). She explores the possibility that women can internalize ideals of femininity present in Western society so that "makeup and dress become tools for their self-accomplishment, mirrors instruments for the satisfactory completion of their femininity" (415). In some ways, through fashion blogging, "surveillance by and of women is legitimated, its presence and its role in daily life is further banalized" (Rocamora "Personal Fashion Blogs" 418). Finally, Rocamora ("Personal Fashion Blogs") draws on the issue of hegemonic femininity. While many fashion bloggers are celebrated for their "model-like appearance," the existence of popularized female bloggers that very closely conform to hegemonic ideals of femininity further perpetuates unrealistic expectations for women and their bodies within the fashion world (421). Ultimately, though, Rocamora argues that the majority of bloggers do not conform to traditional beauty standards with regard to physical traits (421).

\section{Contemporary Fashion Tastemakers and Relations of Power}

Matthews defines taste as "an ability to judge and discriminate on aesthetic and cultural matters" (52). This understanding of taste is helpful to my discussion. Matthews, Connell, Crewe, Entwistle and Rocamora, Rocamora ("Hypertextuality and Remediation"), and Engholm and Hansen-Hansen locate traditional fashion authority with fashion designers, fashion forecasters, buyers, fashion magazine editors, and high profile consumers, like celebrities. These fashion experts are tastemakers within the fashion industry. Matthews argues that, "with their language and images, fashion tastemakers filter fashion information, influence aspects of fashion 
discourse, and bring the focus of attention to a specific set of new fashion items" (54). She also suggests that within the fashion industry, taste is in constant flux and requires consistent production in order to remain relevant (52). Importantly, those that possess "certain social credentials within the "community of taste" in the fashion industry instruct community members on good taste, allowing for a smooth transition to take place from one taste to another (52). Fashion tastemakers gain this status through "a complex series of activities and negotiations, through which they have accumulated a combination of knowledge, expertise and in some cases rare competencies" (Matthews 57). What is important to note here is that becoming an influential tastemaker in the fashion industry is not a simple process; it requires social, economic, and cultural clout as well as diverse knowledge of trends and aesthetic discrimination to move to the top. Notably, then, "these individuals have power within the fashion media context" (Matthews $57)$.

Several theorists have discussed the decentering of these conventional fashion experts that piggybacked the rise of new media technologies (Crewe, Rocamora, Connell, Cover, Pham, McQuarrie et al., Corcoran, Entwistle and Rocamora, Sedeke and Arora, Meyers). Fashion blogging has, in a sense, "diluted the power of mainstream fashion tastemakers and created a symbiotic relationship between mainstream and virtual fashion communities" (Rocamora qtd. in Connell 210). Crewe suggests that upon the advent of fashion blogging, fashion authority has shifted away from "traditional power brokers" and "towards a more diversified assemblage of participants, including bloggers and consumers" (762). Traditional producers of fashion knowledge have previously had full control over the ways that fashion was produced and circulated through media and advertisements, but the online fashion community has opened up these channels of communication to new influencers that perhaps do not have the same 
conventional type of expertise that traditional tastemakers do (Crewe 766). In this way, "the Internet is enabling the disintermediation (or at least reconfiguration) of 'trusted' fashion intermediaries and knowledge providers and is reworking the relationships between producers, the media, and consumers" (Crewe 769). Producers and consumers of fashion knowledge are "becoming more closely aligned in terms of knowledge, power, and authority" (768). Crewe ultimately argues that, "the practice of blogging has enabled industry outsiders who may have no professional affiliation nor any formal qualifications to stand alongside established fashion intermediaries... shattering established hierarchies and modes of knowledge circulation" (772).

Alasuutari et al. find that people are becoming more interactive in the new media environment, welcoming new forms of knowledge production (457). Loader and Mercea argue that citizens are now able to "challenge the monopoly control of media production and dissemination by state and commercial institutions" and instead be critical of it and even share their own opinions on matters that resonate with them (759). Cover suggests that there has been a "pluralisation of sources of authority" within the new media environment (179), which means that power relations are shifting and power is being distributed more broadly across social groups. Pham (“Archival Intimacies") describes the increased ability for participation within the production of fashion knowledge as a "dynamic archive" which includes histories and opinions traditionally silenced (117). Meyers describes the blogger as an audience/producer, a “'produser' that exists outside [the] traditional professional media producer class and threatens its commercial and cultural dominance" (1023). Importantly, she suggests that bloggers "exist outside the boundaries and control of [the fashion] system, but are having an increasingly profound impact on the way it operates" (1029). Bloggers are able to challenge the idea that only professionals or experts can control the production of fashion knowledge, leading, to some 
extent, to a potential flattening of power relations in the industry. Sedeke and Arora note that, "fashion bloggers are looked upon skeptically by the fashion industry as they may not have the proper expertise guaranteeing quality and credible reporting” (par. 1). Notably, businesses and high-profile actors within the industry have lost control of the fashion information that is disseminated with the growing popularity of fashion blogging, proving the threat that blogging posits to a meticulously controlled and regulated industry (Sedeke and Arora par. 4). In this way, the largely hegemonic and capitalism-promoting fashion system stands to be challenged by the growing influence of non-professional or amateur tastemakers like bloggers.

\section{The Perceived Authenticity of Fashion Blogging}

One aspect of fashion blogging that has repeatedly been discussed in theorizations about their democratic potential is the concept of authenticity. New participatory media platforms like blogs gave individuals who began as audience members the chance to contribute to the public fashion world (Meyers 1036). Rocamora (“Hypertextuality and Remediation”) proposes that, "the rise of the fashion blogosphere has resulted in the coming to prominence and the growing influence of individuals who had no institutional affiliation to the field of fashion when they started their blog" (99-100). This notion implies that fashion bloggers are, in fact, real and authentic people who have chosen to express their sartorial style and personal taste online in the form of a blog. Rocamora ("Hypertextuality and Remediation”) further suggests that, "fashion blogs are often seen as the one space where real fashion, fashion as worn by real people, can be seen" (102). This notion is furthered by the idea that the World Wide Web is an unmediated place in which anyone can choose to post content publicly, whereas traditional media outlets are viewed as mediated by “symbolic barriers and conventions," like the newsreader's desk (102). Blogs and their facilitation of user-generated content are often viewed by consumers as a much 
more real and relatable form of fashion media. Engholm and Hansen-Hansen suggest that the fashion blog has placed significant emphasis on the fashion consumer as the creator of fashion content (140). Street style fashion blogs provide a glimpse into the world of what real people are wearing on an everyday basis, allowing readers to "experience authentic presentations of actual street trends" (Engholm and Hansen-Hansen 145). Within the total fashion system, fashion blogging has come to be seen as an opportunity to break down the "historical monopoly of the fashion magazines in disseminating fashion" (150).

Pihl and Sandström's research explores the tendency of fashion blogs to draw readers in using the lure of authenticity. Fashion bloggers often create a story for readers in their posts, allowing readers to feel as though they are catching a glimpse into the author's real life (318). In this way, "fashion bloggers, because they put fashion products in a private and personal context, can be more reliable for consumers than traditional forms of marketing" (Pihl and Sandström 321). Readers feel as though they are building a relationship with the bloggers (318) and, in turn, feel as though it could be their own blog that became popular, or their sister's blog, or friend's, and the list goes on. Rocamora ("Personal Fashion Blogs") argues that, "following a personal fashion blog means not only discovering the sartorial style of its author, but also regularly finding out a bit more information about her life, the moments and events that punctuate it" (412). Pham ("I Click and Post and Breathe") discusses that fashion blog photographs are often shot in very public places, like street corners and crosswalks (236). She further argues that, "the everydayness of these settings is a deliberate aesthetic counterstrategy that locates authentic style in the everyday social life of ordinary people rather than in the tightly guarded institutions and norms of luxury fashion" (236). This allows consumers to feel as though the fashion on display in fashion blogs is achievable for regular, everyday people because the fashion blogger is located 
in the same world. Pham ("I Click and Post and Breathe") asserts that for many bloggers, "outof-place hair, a funny expression, a blurred image, or sun glare are not considered flaws but evidence of the authenticity of the subject, the style, and the moment" (237). In this way, fashion blogs are often viewed as a more trusted form of fashion media, facilitating their growing popularity within the industry.

\section{Blog Professionalization, Brand Collaboration, and Mutually Beneficial Relationships}

While the potential for fashion blogging to be a major stepping-stone in the creation of a more inclusive fashion market is a very real possibility, many theorists also draw attention to some of the obstacles standing in the way of democracy. Pham ("Blog Ambition") does not imply that the blogging platform is entirely repressive, but she states that the blogosphere is "structurally antidemocratic" due to its tendency to become increasingly integrated into and saturated by capitalist logics (2). She argues that, "the configurations of knowledge, communication, and social relations in the blogosphere operate within admittedly restrictive and inequitable conditions" (2). Connell discusses the pervasive difficulty of unseating established hegemonic discourses within the fashion industry (219) as they are facilitated by the "powerful and insidious dynamics that maintain uneven regimes of power" (221). She proposes that there are often social barriers preventing complete participatory democracy on the Internet, creating "homogenous community clusters in virtual space" (Burkhalter qtd. in Connell 220).

Crewe's research suggests that the lines between professional and nonprofessional blogs are becoming more and more blurred as fashion blogging gains popularity, which draws questions about the position of fashion bloggers within the industry (773). The concern then becomes whether or not fashion bloggers be viewed as more authentic than traditional media sources if they are being influenced by and integrated into the same power hierarchy that has 
existed in the fashion industry for centuries. Crewe argues that when a blogger gains enough popularity, the temptation, "for both brand and blogger, is to develop a more collaborative and advertorial relationship" from which both parties can benefit (773). Ultimately, she goes as far as to suggest that perhaps this increase in consumer participation is, in reality, "little more than capitalism's latest tactic to co-opt the consumer in the relentless pursuit of surplus value creation" (777). Sedeke and Arora and Pihl and Sandström both discuss the realization that brands have come to that within the blogging platform, they have "increasingly less control over information concerning their activities and reputation" (Sedeke and Arora par. 5). This led brands to approach bloggers in the hopes of gaining back some of this control. Popular bloggers increasingly began to cooperate with brands, which "creates a circular process where due to their new found status, they gain insider 'professional' knowledge via businesses and brands" (par. 23).

Engholm and Hansen-Hansen discuss the tendency for "Fashiondustrias" to become popular within the fashion blogosphere, which are bloggers who are fashion industry professionals, like stylists, models, or photographers (143). Their research does indicate the existence of amateur bloggers who blog about themselves "who have been 'discovered' by the fashion industry and gained access to the professional fashion events" (143), but they argue that these bloggers reproduce "many of the hierarchies and traditions familiar from the fashion industry" (144). Because it is difficult to be recognized by the industry as an amateur blogger, "the few bloggers who manage to obtain access to a luxury fashion media event achieve a kind of blogger celebrity status, with a large army of readers" (Engholm and Hansen-Hansen 144). The authors suggest that if a blogger becomes successful, they begin to collaborate with or are incorporated into the established fashion media system (146). Importantly, the system runs on a 
"rich-get-richer effect" in which "some fashion blogs are repeatedly highlighted as cutting edge, producing favourable conditions for them to achieve more preferential attachment from other bloggers, newspapers, and fashion magazines" (151). In this way, the traditional fashion media uses bloggers as "hubs" (Engholm and Hansen-Hansen 151). In this way, the few fashion bloggers that gain mass popularity can make money by exchanging services, like advertisements or recommendations, with fashion houses, brands, and media (151). In addition, if a blogger has any hope of continuing to gain recognition within the industry, "she must refrain from criticizing the major fashion producing firms" (152). This idea implies that often blog content produced by very influential bloggers is biased because the blogger has entered into an unspoken contract with companies that have gifted them merchandise or paid for their influence.

Similarly, Pihl et al. argue that fashion blogs often contain a mix of private and commercial content (309). Pihl et al.'s research explores the potential that bloggers have to create value for themselves by using their popularity and content. He suggests that, "to be commercially successful, bloggers must create value for consumers and also be able to capture this value somehow" (312). Correspondingly, then, bloggers are able to make money through advertisements on their sites or by creating their own brands or online stores (321). In order for significant value to be created, the blogger must have a large following (321). Pham's ("Blog Ambition") research further explores this topic, suggesting that the entire structure of networking systems is "fundamentally antidemocratic" because, the majority of the time, certain forms of wealth and power are required in order to increase blog popularity (2). For example, a blogger with disposable income is able to utilize expensive search engine optimization services that “artificially drive up the ranking of one's blog or Web site by manipulating the number of hits the site receives" (2). Pham outlines the pitfall of the Internet's participatory nature, reminding 
us that "only the most popular Web sites and blogs are likely to show up in Web searches," making it more of a "democracy of popularity than equitability" (6). She references Jodi Dean, who argues that capitalism is to blame for the antidemocratic structure of the Internet. Instead of an equitable search in which "any one point is as likely to be reached as any other, what we have on the Web are situations of massive inequality, massive differentials of scales where some nodes get tons of hits and the vast majority get almost none" (6). Pham ("Blog Ambition") also touches on the mutually beneficial relationship that most bloggers have with powerful fashion influencers. While being recognized by a popular blogger lends a brand "hipster credibility" as well as cheap global marketing and advertising, reciprocally, being recognized by a fashion giant brand lends status and power to a blogger (12). This recognition gains the blogger more followers and increases the likelihood that "people will read and solicit the blogger's future online and offline publications" (Pham 12).

A good example that Pham ("Blog Ambition") uses to illustrate the collaborative relationship that bloggers have with traditional fashion power brokers is a 2007 Chanel trip to Paris in which the fashion house invited twelve prominent bloggers to learn about the history and influences of Chanel (11). Pham discusses that blogger Susie Lau (aka StyleBubble) writes on her blog that although there was no obligation to blog about their experiences, "Lau clearly understands that there is an unspoken social contract informally conditioning bloggers' access to the fashion industry" (11). Brands and other fashion influencers have realized that in order to regain control of the industry, they must work alongside bloggers to build a discourse around trends. In discussing fashion bloggers' roles as tastemakers, Matthews argues that, "discourse about a fashion object is not established merely with a couple of statements; instead, it must appear across a range of texts" (59). In this way, it is easy for a brand's product to be lost in the 
Internet's vast amount of information (60). Matthews argues that, "this makes the fashion object's association with high profile fashion tastemakers essential, because being able to trace the object back to a statement by a legitimate fashion tastemaker not only is an endorsement, it amplifies the message" (60-1). In identifying trends, bloggers must be cohesive in their endorsements. Often, bloggers look to one another or to brands for tastemaking direction, as "consensual legitimation of trends is imperative in the formation of taste, even for expert fashion tastemakers" (Matthews 62). Finally, Matthews argues that, "this activity conserves the operations of the fashion system by allowing consensus to emerge, while legitimizing the tastemakers' positions in fashion media through mutual recognition" (61-2). For this reason, the question of the authenticity of fashion blog content remains paramount in my research surrounding the democratic potential that fashion blogging has within the industry. 


\section{Methodology AND THEORETical FRamework}

\section{Pierre Bourdieu: Habitus, Field Theory, and Capital}

Building on the work of Pierre Bourdieu, I will analyze the democratic potential of fashion blogs through the lens of concepts of capital. Bourdieu's work began with his realization and belief that individual perception shapes everything we know about the world, but that these structures actually consist of:

Defining principles which are both pre-constructed and evolving according to the logic of differentiation found within the social universe. In other words, such principles do not exist in some value-free Platonic realm; rather, they are the product and process of what already-has-been-values which serve the status quo and/or emerging social forms. (Grenfell 45)

In simpler terms, Bourdieu suggests that individual perception of the world is shaped by preexisting structures that determine said individual's place or rank, thereby influencing the individual's decisions, actions, and potential. Maton explains this idea by suggesting that although we often feel like we are free to make our own choices, we consistently base these choices on what we think others will do, think, or say about them (50). For example, there are unspoken rules or regulations that presuppose that a working-class child will grow up to have a working-class job (Maton 50). Bourdieu's work set out to explain how social practices became controlled by regularities; he asks how "behaviour [can] be regulated without being the product of obedience to rules?" (qtd. in Maton 50). Central to this discussion is his concept of habitus.

Maton, a professor of Sociology at the University of Sydney, discusses Bourdieu's concept of habitus, suggesting that habitus is a "property of social agents" which could be individuals, groups, or institutions, that encompasses a "structured and structuring structure" (51). He maintains that it is structured by circumstances, like a person's education or family life, 
is structuring because it shapes a person's present and future actions, and is a structure because it is a system of order rather than of changing patterns (51). Further, "this 'structure' comprises a system of dispositions which generate perceptions, appreciations and practices" for people living within it (Maton 51). Importantly, Maton tells us that, "the habitus is thus both structured by conditions of existence and generates practices, beliefs, perceptions, feelings, and so forth in accordance with its own structure" (51). Bourdieu argues that the habitus acts in relationship with a field. Maton describes this relationship, suggesting that, "practice results from relations between one's dispositions (habitus) and one's position in a field (capital), within the current state of play of that social arena (field)" (51). In other words, actions take place in a person's life as a result of their habitus in relation to their current social environment and their place within it. In this way, according to Bourdieu's concept of habitus and field, we as people make decisions based not only on present circumstances, but also based on our histories in which past events shape the way that we respond and react to situations as well as the choices we make. Maton tells us that, "this range of choices depends on our current context (the position we occupy in a particular social field), but at the same time which of these choices are visible to us and which we do not see as possible are the result of our past journey, for our experiences have helped shape our vision" (52).

An important discussion to engage with next, then, is Bourdieu's concept of field. Thomson, a scholar and professor of Education at the University of Nottingham, discusses Bourdieu's argument that in order to truly understand social practices, it is imperative to look at the "social space in which interactions, transactions and events occurred" (67). She states that: According to Bourdieu, an analysis of social space meant not only locating the object of investigation in its specific historical and local/national/international and relational 
context, but also interrogating the ways in which previous knowledge about the object under investigation had been generated, by whom, and whose interests were served by those knowledge-generation practices. (67)

Bourdieu called this the social space field (Thomson 67). Bourdieu called social agents (people or institutions) in each specific cultural field "players," and each had a specific role and position within their respective field (68). He suggested that players had limits on what they could accomplish based on their position and the condition of the field they were in (Thomson 69). The field can be viewed as a competitive social environment in which players can engage in different approaches to improve their position (69). Players vie for what Bourdieu called "capital" within their field, which exists in four forms: economic, cultural, social, and symbolic (Thomson 69). Importantly, though, "players who begin with particular forms of capital are advantaged at the outset because the field depends on, as well as produces more of, that capital" (69). In this way, those players that came into the field with capital to begin with are more likely to achieve success within the field because they have the added advantage of pre-conceived capital (69). Therefore, fields are not equal and some players are better equipped for success than others. Bourdieu viewed fields as somewhat exclusive, privileging insiders and making it difficult for outsiders to enter (Thomson 70). Different social agents within each field occupy different ranks and can influence others' involvement in the social practices of the field (70). Players that occupy higher field rankings have more capital (economic, social, cultural symbolic) than lower field rankings, which provides them with the most power and influence within that particular field. This constant reproduction of inequality within a particular social field is not often recognized by field members because the "doxa in each field operates to misrecognize its contribution to the overall field of power" (Thomson 73). Significantly, then, power is 
consistently reproduced and fostered within a particular field to maintain the status quo and to reproduce systems of inequality and hegemony to favour the ruling class; possession of capital within a field results in the accumulation of further capital and, consequently, power (Thomson 73). This discussion of field relates back to the concept of habitus so that personal history, current field ranking, and capital intersect to determine the way in which social events are shaped (Thomson 74).

Moore discusses Bourdieu's theory of capital as Bourdieu's attempt to draw attention to capital as not only a form of economic exchange, but as a wider system of exchange across varying cultural fields (102). He tells us that Bourdieu lists two main distinctions between forms of capital: economic capital and symbolic capital, which can be broken down into social and cultural forms of capital (103). Economic capital has no intrinsic value, but is "always only a means to an end (profit, interest, a wage, etc.)" (Moore 103). This is true for symbolic capital as well, but forms of symbolic capital deny this association and promote themselves as having intrinsic worth and no ulterior motive (Moore 103). For example, within the field of the arts, cultural capital is reflected in the intrinsic value of certain pieces of art. Those who are gifted with the ability to discern between pieces and recognize this intrinsic value are endowed with cultural capital or distinction (Moore 104). Ultimately, though, Moore references Bourdieu's argument that all forms of symbolic capital are inherently linked to economic capital and the possession of one or more types of symbolic capital leads to the growth of a person's economic capital as a result of the power that this possession entails (104). In this way, symbolic capital legitimates a system of subordination and social domination in which those that possess this form of capital gain further capital and therefore more power whereas those with little symbolic capital rarely achieve success as a powerful actor within their respective fields (104). Moore 
suggests that Bourdieu attempts to describe symbolic capitals as "types of assets that bring social and cultural advantage or disadvantage" (104). In this way, "each field of symbolic capital reproduces the system of unequal relations in the economic field (relations of class and power) and, in doing so, reproduces the fundamental structure of social inequality" (Moore 104). Bourdieu's concept of distinction posits that any particular person will make aesthetic or cultural selections based on their own personal habitus (Moore 108). The ability to make selections based on the intrinsic value that the cultural product apparently holds within a given social setting is a gift that is possessed only by those with enough symbolic or cultural capital to discern the product's value, thereby giving that player within the cultural field a form of distinction (108). Distinction is then transferrable to various forms of capital, granting the player with distinction power within the field (108). This is a circular process and ultimately facilitates consistent social inequality within cultural fields (108). According to Bourdieu, cultural products or items do not have legitimate intrinsic value; rather, it is the endorsement of these products by players with distinction that gives the cultural products an illusion of intrinsic value and legitimates their place within the field (108), which is very relevant within the field of fashion. Importantly, forms of symbolic capital are heavily dependent on habitus and on the potential a player has had in their past to gain knowledge about the field through education and social connections (Moore 109). In this way, economic capital is not synonymous with symbolic capital; rather, forms of symbolic capital like cultural and social capital are most often a result of a person's habitus (109). Moore suggests that, "the inequalities associated with cultural capital reflect inequalities in capacities to acquire capital which themselves reflect prior inequalities in the possession of cultural capital" (109). Symbolic capital's acquisition cannot be separated from the person and has to be acquired over time, which differentiates symbolic capital from economic capital (109- 
10). In this way, those players that possess one or more forms of symbolic capital within their field are the most advantaged.

\section{The Field of Fashion}

Rocamora ("Fields of Fashion") discusses Bourdieu's work in relation to the fashion industry. She suggests that, "the field [of fashion] is defined by the unequal distribution of specific capital" amongst important players within the field and, correspondingly, "the specific capital at play in the field of high fashion could be called fashion capital" (343). She argues that those with symbolic capital within the field of fashion, like designers and couture houses, magazine editors, and buyers, demonstrate exhibits of aesthetic taste that solidify their power within the industry (351). In discussing Bourdieu's ideas of intrinsic cultural value, Rocamora ("Fields of Fashion") brings up Bourdieu's discussion of labels. Bourdieu argues that the label "operates a process of transubstantiation of the material object to which it is applied, which then

takes on the high value attached to the name" (348-49). In this way, then, the label cannot change the material value of the object, but instead changes its symbolic value (349). Fashion products gain symbolic value within the field through their association with labels or people with distinction (and therefore power) in the industry (349).

In a study of London Fashion Week, Entwistle and Rocamora argue that the primary roles of fashion weeks are to "produce, reproduce and legitimate the field of fashion and the players within it" (736). Most relevant to my discussion is their dialogue surrounding the importance of prominent players within the field of fashion to see and be seen at these events, particularly in the front row (737). In these settings, these powerful players exhibit their "fashion capital and habitus" as part of their performance of power within their role (737). In fact, some players hold so much power that the fashion show will not start until that particular player is 
seated (742). Fashion bloggers are often viewed as important players and are gifted front row seats by brands and fashion houses. By being seen at the show, fashion players legitimate and reproduce their position of power in front of other important players in the field (Entwistle and Rocamora 743). Entwistle and Rocamora go as far as to suggest that, "visibility in this arena translates into power: the more powerful bodies are the most visible in the front row" (744). This visibility translates into power in the digital sphere as well, as the most visible bloggers at major fashion events gain readership and blog hits, which leads to further accumulation of both symbolic and economic forms of capital.

\section{Bourdieu and Fashion Blogging}

Rocamora ("Pierre Bourdieu: The Field of Fashion") argues that within the field of fashion, bloggers are newcomers and are attempting to gain influence or distinction within it (234). She also suggests that, "newcomers are dependent on their experience... to generate 'an initial capital of authority"” (240). Importantly, then, Rocamora ("Pierre Bourdieu: The Field of Fashion") goes on to say that fashion bloggers gain cultural capital through their ability to put together fashionable outfits, which is heavily dependent on distinction, and therefore also on both economic and symbolic forms of capital (240). In this way, then, Rocamora ("Pierre Bourdieu: The Field of Fashion") argues that, "the seemingly democratic virtue of blogging as an activity simply open to all with a computer may veil the key role a privileged capital such as one's model-like body can play in one's successful entry into the field of fashion" (247).

My research also takes into account the work of McQuarrie et al., who discuss a concept called "the megaphone effect", which describes the phenomenon in which the Web has made it possible for ordinary people who do not have any professional experience or institutional/familial ties to reach mass audiences through posting about consumption (137). 
McQuarrie et al. also draw on Bourdieu's theory of capital in their research, which will also act as a model for my own analysis. McQuarrie et al. propose that, "once a consumer gains a large audience, this can be converted into institutional access and further leveraged thereby" (137). Another beneficial point that will aid in my own research is their analysis of fashion bloggers' use of accumulated capital. They suggest that often, bloggers will accumulate a particular form of capital in order to convert it into a different form, investing it like money (139). Once you have one form of capital, other forms are more easily obtained in the future. This idea may help explain how successful bloggers continue to pursue further capital, such as gifted merchandise and brand collaborations, after they have already gained large audiences. McQuarrie et al. suggest that fashion bloggers are a form of cultural capitalists, who use displays of taste to gain cultural capital, which is then converted into economic capital, among other forms (153). Their study emphasizes that the increase in opportunity for regular people to appear in the media (the demotic turn) is not indicative of the democratization of power within the fashion industry (154). Importantly, the concept of the megaphone effect will enhance my research around how fashion bloggers obtain readership and popularity and will further influence my analysis of the democratic and participatory truth of fashion blogging.

The Blonde Salad Blog Case Study and Analysis

To illustrate my ideas and findings as well as to add a layer of complexity and reality to my analysis, I will conduct an in-depth case study of one popular fashion blogger. Chiara Ferragni, also known as the author and creator of TheBlondeSalad blog, will be the subject of my analysis. Chiara was born in 1987 in Cremona, Italy (Ferragni "About"). She began sharing her non-professional photos that she took with her friends in online communities and gained popularity rather quickly. In 2009 at the age of 22, she took the next step and launched her blog, 
www.TheBlondeSalad.com. Today, Ferragni has an array of successes within the fashion blogosphere, including collaborations with major fashion design houses, features in big fashion magazines, the launching of her own shoe line, and being named by Business of Fashion as one of the most influential personalities in the international fashion world (Ferragni "About"). I have chosen to analyze The Blonde Salad blog in the hopes that it will be generally representative of the influences at play in other high profile fashion blogs and their authors. I will adopt a netnographic approach, as utilized by Scaraboto and Fischer in their study of plus-sized fashion bloggers, to analyze TheBlondeSalad blog. I will perform an in-depth analysis of a chronological selection of twelve of her posts, coding for patterns, similarities, and differences between them in textual and visual content (Scaraboto and Fischer 1240). I will collect qualitative research consisting of observation, reading, and archiving of blog posts. Blog posts will then be coded accordingly, looking for links to other posts as well as references to products and marketing attempts to determine the sociocultural influences at play within them. Following this analysis, I will apply the previously discussed theories and research to my analysis of TheBlondeSalad blog. From here, I will be able to analyze my results and discuss them with respect to my research questions and objectives as well as my theoretical framework.

\section{Anticipated Outcomes and Contributions}

This interdisciplinary project hopes to reveal the power relations that are at play between fashion producers and consumers by gathering and analyzing data on the idea that new media forms, like blogs, have the potential to create a more democratic fashion market. My research will utilize existing theoretical concepts to develop a comprehensive analysis of the possibility that fashion blogging could decenter the voice of traditional fashion experts when it comes to the production and distribution of fashion knowledge to the public, changing the field of fashion 
entirely. I anticipate that this research will reveal hidden or disguised truths surrounding the distribution of power within fashion media forms, particularly within fashion blogging as a genre. I anticipate that much of the participatory potential that the process of fashion blogging offers is awarded to only a select few bloggers that achieve wide success. As Engholm and Hansen-Hansen suggest, "a few blogs have many readers, while most blogs have few readers" (151). I anticipate that my research will shed light on the implications of this statement and will be a valuable resource for future research into fashion blogging and democracy as well as comparative studies between the most 'famous' and widely read fashion bloggers and those who do not possess as much economic/symbolic capital within the field. 


\section{ANALYSis AND Discussion}

\section{The Blonde Salad: An Introduction to my Case Study}

To illustrate and analyze some of the secondary research presented in my Literature Review and Methodology, I have conducted some primary research in the form of a case study on a blogger named Chiara Ferragni, also known as The Blonde Salad. In the "About Us" section of the Blonde Salad website, there is a "Chiara Ferragni”" tab in which Chiara's life and blog progress is briefly outlined. In this section, it states that Chiara "inherited from her mother the passion for fashion and photography" (Ferragni “About"). It goes on to discuss her influence within the fashion industry today and informs readers that she was named by Business of Fashion and Forbes magazines "as one of the most influential personalities of the international fashion world" (Ferragni "About"). This information page also contains a scrollable timeline that showcases where Chiara was in her blogging career ranging from the year 2006 during which she started posting photos on various online communities, to the year 2016, during which she became the face of Pantene and Amazon Fashion international campaigns (Ferragni “About"). The blog provides a somewhat limited background on Chiara's life and accomplishments in this section, but nevertheless emphasizes her importance in the world of fashion. The information provided here is quite general and often lacks specificity. Rather than being a comprehensive overview of her accomplishments, it is a brief summary of some of the main points.

Despite its generalized nature, this section does succeed in establishing Ferragni's status as an influential insider in the field of fashion. It lets readers know that she is an important player within the field and also legitimizes her role as a tastemaker with distinction in the fashion industry. Bourdieu's idea of distinction implies that a gifted player within a particular field has been recognized as being able to discern the value of cultural objects, in this case, of fashion objects (Moore 104). Ferragni's numerous awards, collaborations, advertising campaigns, 
magazine covers, as well as her own personal shoe line and extremely large fan base (over 8 million Instagram followers, according to Glamour magazine) all contribute to awarding her distinction in the field. The main purpose of this section of the blog is to let readers know the status of the blog itself and its founder within the field of fashion. Ferragni's status in the field works to increase reader respect and therefore gain more loyal blog subscribers that read the blog on a regular basis. In doing so, this section lays the groundwork for further accumulation of both economic and symbolic capital for the Blonde Salad blog and for Ferragni herself.

It is important to mention that old posts are difficult to find and navigate on the current Blonde Salad blog. Going back several years requires copious amounts of scrolling and time commitment on the part of the reader. One reason for this may be because of the fashion blog platform itself, as older posts are less relevant to current trends in the fashion industry, therefore readers may be less interested in out of date posts. I propose that another reason that old blog posts are difficult to find is because they are amateur in comparison to current blog posts, which lends less credibility to the Blonde Salad brand. In some ways, I would suggest that the amateur photography as well as typing and grammar errors in early posts by Ferragni damage or hinder the perpetuation of her status as a leading player within the field of fashion today. Perhaps this is another reason the Blonde Salad team has chosen not to make early Blonde Salad blog posts overtly accessible to the average reader. Additionally, the format of the blog has changed many times and reflects movement and advancement of Chiara's fashion career. It is not in the scope of this research to discuss more than the twelve posts I have outlined here, but I will provide a brief description of the blog as I have experienced it today during the period of January 2017March 2017. 
When Ferragni began the blog in 2009, she posted on a regular basis (usually once or twice per day). Posts consisted of life updates and outfit descriptions of what she chose to wear for different events happening in her life, which were accompanied by fairly amateur photographs of her outfits. She included photos with her friends and her boyfriend at the time and these photos were usually quite casual and playful. Ferragni herself authored all posts. By mid-year 2010, the photographs became better quality and are less playful. More of her outfits were highlighted and the posts focused mainly on the clothing she donned rather than what she was doing that day. She still provided life updates and authored all her own posts, but the shift in focus of the blog can be viewed as beginning.

Moving into the years 2011 and 2012, the posts were still authored by Ferragni and they did provide life updates, but these updates were almost always in the form of an outfit post that also happened to describe what she was doing on that particular day. The photographs become much better quality as well; they appear as though they were no longer taken by a complete amateur, but were instead taken by someone familiar with fashion photography. Ferragni's poses were becoming more and more advertorial and sophisticated in these posts. The posts were very focused on her outfits and on various aspects of the outfits that she wanted to highlight. As I will discuss, one of her 2012 posts described the success of her fashion blog and her own endeavors since starting it. It is evident that she had made significant progress in only three short years. The year 2013 became an important one for Ferragni and the Blonde Salad blog, as is described in detail in her "Best of 2013" post. During this year, her long-term relationship ended and another began. She collaborated with countless brands, participated in many professional photo shoots in which she was the model for big name campaigns, travelled around the world, had the best year yet for her shoe line sales, won prestigious awards, and grew her TBS crew team (Ferragni, 
"Best of 2013"). These changes are evident in her posts from the years 2013 and 2014. All photos were professional and were taken by a photographer, usually listed at the bottom of the post. Ferragni's own poses demonstrated confidence and her outfits were changing as well; as the years progressed they became increasingly high fashion and exclusive, demonstrating her accumulation of both economic and symbolic capital.

The last half of the year 2014 and into 2015 is a time in which posts authored by Ferragni herself became harder to find on the Blonde Salad blog. Instead, the TBS Crew or various contributors from the team had written many posts. Posts became less about Ferragni's life and more about the Blonde Salad as a brand or a company. The blog became less of a personal style blog for Chiara and more of a lifestyle blog managed by a team of people representing the Blonde Salad as a brand. Many of the posts during this time contained advertisements for Ferragni's own brands and collaborations. Most posts authored by Ferragni contained very little or no text. The same is true for the year 2016; readers hear and experience very little of Ferragni's own voice. Today in 2017, many different members of the TBS crew contribute the blog to several times daily. Post content varies from advice about up and coming trends to outfit posts about what Ferragni wore to a particular event. The site is organized in tabs: Shop, Fashion, Beauty, People, Lifestyle, and Talents. Each tab contains subsections that readers can click to navigate through posts. The 'Shop' tab allows readers to shop Ferragni's collaboration and personal fashion collections directly from the site. Advertisements litter the screen for many different brands. The Blonde Salad logo is very prominent and advertisements for the site itself are present as well. From here, I will discuss twelve of the posts in detail to try to give an accurate picture of the evolution of the blog from its inception in 2009 to March 2017. Posts for Analysis 


\section{“Here I Am!” (12 October 2009)}

The very first post that The Blonde Salad blog ever made was a post authored by Ferragni herself dating back to October 12, 2009. The post contains the same text in both English and Italian. In this post, she tells her readers that the starting of this blog was "driven by needs of communication and personalization" (Ferragni). She explains that after using Flickr for several years to share her pictures, she felt she had to "move on and create a space for [her] own" (Ferragni). She tells her readers that she plans to call the blog “"The Blonde Salad' because this blog is gonna be a salad of myself" (Ferragni). Further, she mentions that, "the ingredients will be those which have always characterized [her]: fashion, photography, travel, and lifestyle" (Ferragni). In closing, she signs "C.F." and ends the post. There is one photo included and it pictures her (shoulders up) naked and holding a Barbie doll (see Figure 1). The Barbie is also

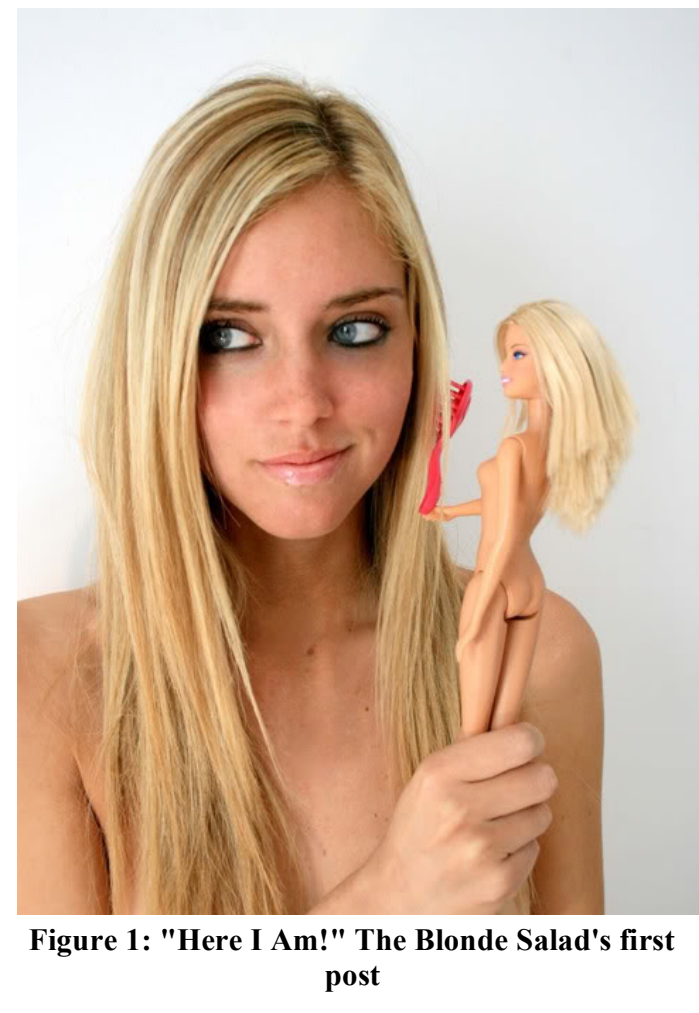
naked and is holding a red brush as Ferragni holds the doll up to her hair, pretending the Barbie is brushing it. The photograph appears to have been taken either by someone else or with the use of a tripod, but it also appears amateur.

This post lends credibility to the concept of authenticity; Ferragni describes her motivations for creating the blog as a need for further communication with readers and increased personalization of her own online space. In this way, this post addresses Rocamora's (“Hypertextuality and Remediation”) idea that blogging allows individuals with no institutional affiliations to have influence within the 
industry (99). Ferragni creates an image of herself in this post in which she is a regular fashion consumer, albeit one that conforms to an idealized beauty standard (as evidenced in the inclusion of the Barbie doll), who is looking to share her own style sense with others. The post promises that the blog will be very personal and gives readers the impression that they are viewing an authentic portrayal of Ferragni's fashion choices in her posts. She mentions that she is passionate about "fashion, photography, travel, and lifestyle," but she does not mention any professional training or personal relationships that she has with anyone in these fields. Instead, the blog is established as a place in which Ferragni intends to share her fashion choices with whoever wants to see them with no other motive than personal expression.

This is an important aspect for analysis because, aligning with Rocamora ("Personal Fashion Blogs"), Engholm and Hansen-Hansen, and Pihl and Sandstrom's research, Ferragni's fashion blog is depicted as an authentic glimpse into her life and personal style. Readers feel as though they are interacting with Ferragni as the author herself as opposed to traditional forms of fashion media in which content is created and mediated by industry insiders. Instead, Ferragni establishes in this post that she intends to provide for readers a form of fashion media that differs from traditional media forms that are often propelled by the pursuit of capital. By establishing her role as a fashion consumer, Ferragni echoes Engholm and Hansen-Hansen's research, which emphasizes the role of consumers as creators of fashion content through blogging (140). Additionally, Ferragni endears herself to readers by making this post feel like a personal address. She signs it "C.F." and includes an intimate photo of herself in which she is naked. This photo can be viewed as a display of trust in her readers as well as another indication that she is the main voice and influence that the blog will depict moving forward. The personal aspects of this post help to represent the authenticity of the blog as well as the motives of its author for the 
future. It is posts like these that provide blog readers the security that the content they are engaging with was created by a real and authentic person as well as give readers the hope that they too can have influence within the previously closed fashion industry.

\section{"After the Cinema" (14 October 2009)}

This post is authored by Ferragni herself and contains text in both English and Italian. This is one of her first posts. There are ten photos included in the post and they incorporate a friend of Ferragni's, Angie. The photos are of decent quality, but are amateur (not taken by a professional). Following the photos are her outfit details, but the photos appear to be less focused

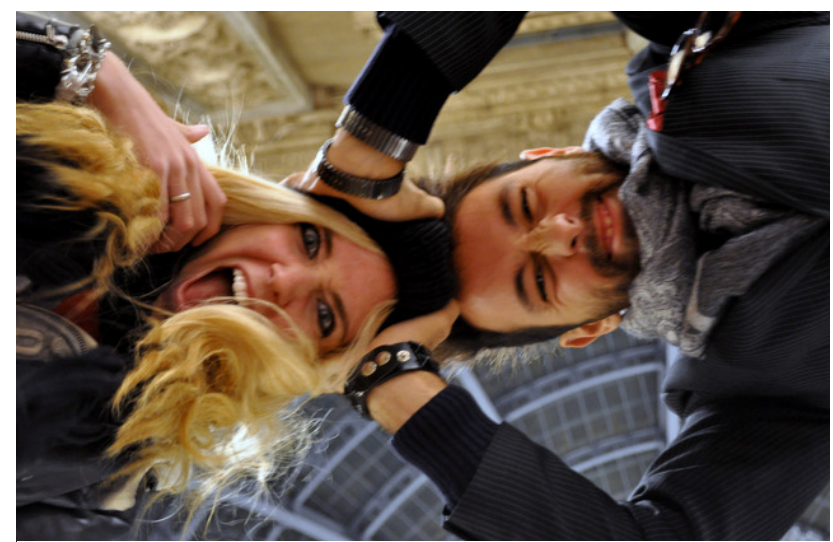

Figure 2: "After the Cinema" Ferragni and friend, Angie on the outfit and more focused on Ferragni herself and her time with Angie (see Figure 3). They are also quite playful and goofy (see Figure 2). They are taken in a public place in Milan, Italy. The post appears to be somewhat of a life update in which she is telling readers where she is in the photos included and what she and her friend Angie were doing. The post is reminiscent of a social media post created for friends. She also speaks directly to readers, asking them for advice, asking if "in posts like this one, where you can see the clothes I'm wearing, should I write down the brands (as almost all the girls do in their fashion blogs) or not?" (Ferragni).

Again, one of the most significant aspects of this early post on the Blonde Salad Blog is the personalized nature of its content. Echoing Pihl's research, Ferragni gives her readers a real glimpse into her life through a post like this (318). She opens her life up to her readers, providing them with not only an idea of what she was wearing to a real event in her life, but also an update 
on her day to day activities and she even introduces one of her friends to the blog. This post is a good example of Ferragni's ability to make herself relatable to readers. Arguably, this authentic form of lifestyle sharing is part of the reason that the Blonde Salad blog gained the popularity that it did. For the purpose of critical thought, the politics of the word 'relatable' as used here should be discussed. Onion discusses that, "when the word 'relatable' really means 'relevant to me,' as it often does... anything outside the purview of 'relatability' looks like it's not worth examining" (par. 7). In other words, the idea of relatability may mean something completely different to diverse groups of people. For the purpose of this paper, I

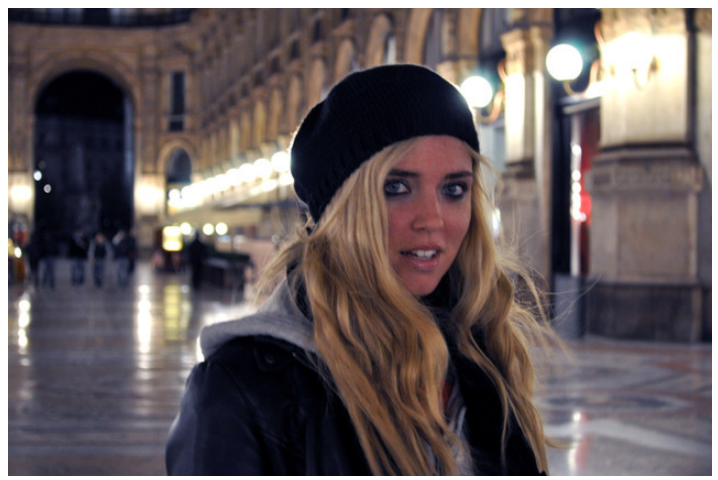

Figure 3: "After the Cinema" Ferragni alone in a square in Milano use the term 'relatable' in a singular way to address the idea that readers of Ferragni's blog may feel, in some ways, familiar with Ferragni and her experiences through the way that she expresses herself in earlier posts. With this context in mind, the fact that the photos are not professionally taken also adds a relatable lens to the post, implying that anyone with access to the Internet and a camera can freely share their sartorial choices with the world. The playful nature of some of the photos reveal Ferragni's goofy and seemingly real-life personality, allowing readers to feel like they are getting to know the person behind the blog. This leads readers to place deeper trust in Ferragni's content.

Another important aspect of this post is Ferragni's direct address to readers. She asks the opinion of her followers, allowing for an open and two-way form of communication to take place. This shows that Ferragni values ideas from her readers and takes into account their expectations of her blog. The "Comments" section of the blog allows readers to respond directly 
to Ferragni as the author and allows readers to feel as though they are having an influence on the blog and on the content that Ferragni is producing. This further strengthens the readers' connection to Ferragni as a real person and demonstrates that she values readers' input and ideas. In addition, what she is asking readers is also relevant. She asks whether or not readers would like to know what brand makes each piece of clothing she wears in her posts. Importantly, this indicates that Ferragni is not yet consciously marketing specific brands, therefore not accumulating capital by wearing certain clothing. This shows readers that outfit choices featured on the blog are of Ferragni's own choosing, further perpetuating the authentic nature of her blog.

Importantly, in this post readers receive a limited view of the capital that Ferragni possesses within the fashion industry. Although the photos are not professionally taken, they are of decent quality and would have thus required a high quality camera to take them. Ferragni would have had to have the economic capital to purchase the camera before even starting the blog. Additionally, the photos depict Ferragni and her friend out for a cinema date in Milan, implying that Ferragni has the economic capital to take trips like this with her friends. Her outfit details in this post tell readers that her shoes are by Converse, her jeans and hat from Zara, and her sweater from Abercrombie. Although these are not luxury items, they still required middle or upper class capital to afford. This tells readers that Ferragni comes from, at minimum, a middle class background. In addition, she is updating her blog on a regular basis with posts like this during this time, implying that she has the financial ability to take the time out of her day to do so. Interestingly, her bag in these photos is by Balenciaga, a luxury fashion brand. Importantly, then, Ferragni was able to purchase or borrow this bag, implying a high level of economic or symbolic capital. The bag also signifies a form of symbolic capital. As a cultural object, Ferragni uses the perceived intrinsic value of the bag through its label or brand to establish herself as 
someone who is able to discern the intrinsic value of cultural objects. Bourdieu would describe this as Ferragni's attempt to gain distinction within the field of fashion (Moore 104). In this way, because Ferragni presumably possessed the economic capital or symbolic capital necessary to purchase or borrow this Balenciaga bag, she was able to leverage this economic capital into symbolic or cultural capital as a result of the power that the possession of this bag entailed. Significantly, Ferragni did possess some important forms of capital from the outset of her blog, ultimately aiding in her success within the industry.

\section{“Milano by Night" (23 October 2009)}

This post, written by Ferragni herself, seems as though it is almost a follow-up post to the "After the Cinema" post previously discussed. Ferragni mentions that it has become "somewhat of a 'tradition"' to go to the cinema with Angie every week. She also tells readers that, "it is really difficult to find places where you can take good photos using neither the tripod (kinda heavy to bring it with me all the afternoon long) nor the flash (I don't really like the effect)" (Ferragni). She again gives readers a life update and asks for advice, saying that she is busy lately studying for an exam in November and asks readers what they would like to $\mathrm{read} / \mathrm{see}$ on the blog in the future. All text is provided in English and Italian. Eight amateur photos are included. Some pictures are blurry and they focus more on displaying Ferragni and the location that she's shooting at than on her outfit (see Figure 4). Her poses in the photos are also quite laid-back and playful.

This post is again indicative of authenticity on

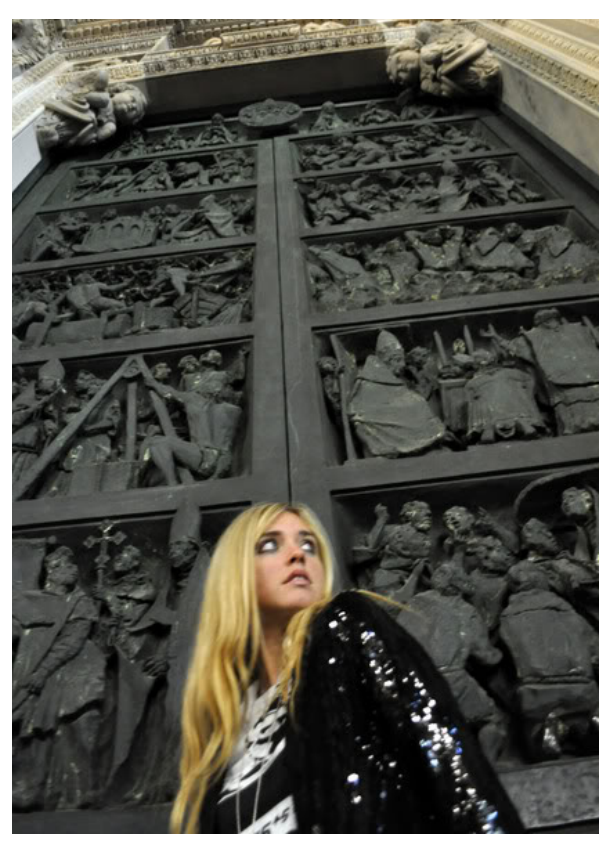

Figure 4: "Milano by Night" Ferragni in Milano 
Ferragni's part. She is expressing personal information about her life to readers. In this post she even mentions some of the struggles she has faced in the creation of her blog content thus far, such as the problem of taking her own photos in a way that she is happy with them or balancing her time as she studies for an exam. Readers catch a glimpse of some human flaw in this post, making Ferragni even more relatable. In the past three posts discussed from the year 2009, Ferragni depicted herself as a regular person with a passion for sharing personal style. In addition, she revealed her access to both economic and symbolic capital within the field of fashion. Her outfit details in this post aid in representing her economic and symbolic capital. For this outfit, she again chooses to mix mid and high fashion brands to create her look. Although she wears an old pair of shoes that she mentions forgetting about before this post, she pairs it with an upper mid-priced pair of jeans and a designer bag (a different Balenciaga bag). These choices impact her accumulation of further economic and symbolic capital and these forms of capital work together in her blog posts to gain her further recognition within the industry and further capital within the field.

\section{“Wearing Miu Miu" (28 May 2010)}

This is a post written by Ferragni highlighting her purchases from the latest Miu Miu collection. She tells readers in both English and Italian, "I loved every single piece of the lates (sic) Miu Miu collection, even if I could only buy the shoes and the collar" (Ferragni). Her words let her readers know her consideration of and deliberation on the outfit. She laments that, "[she] thought that [she] would have had some problems matching the shoes in the different looks but the real problem was the collar: before this day [she] couldn't wear it in a nice combination" (Ferragni). She also mentions that she "decided to tie up [her] hair in a ponytail to give the collar its value" (Ferragni). She continues to ask her readers questions and opinions. There are twenty photos 
included in this post. The photos are of good quality and are focused mainly on her outfit. Ferragni's poses are calculated and emphasize certain aspects of her outfit in the photos, particularly her new Miu Miu cat collar and shoes. She is the only one present in the photos with one photo including a passing dog. The lighting is good and the photos appear to have been taken either by someone else or with the use of a tripod. The photos are taken in a public park. Her stance in the photos appears more professional and is reminiscent of a fashion model's pose in a magazine (see Figure 5). Ruggerone argues that, "the role assigned to female and male [fashion] models is that of interpreting a dress and communicating certain types of messages" through it (355). Arguably, Ferragni's poses in these photos attempt to convey messages about the clothes she is wearing.

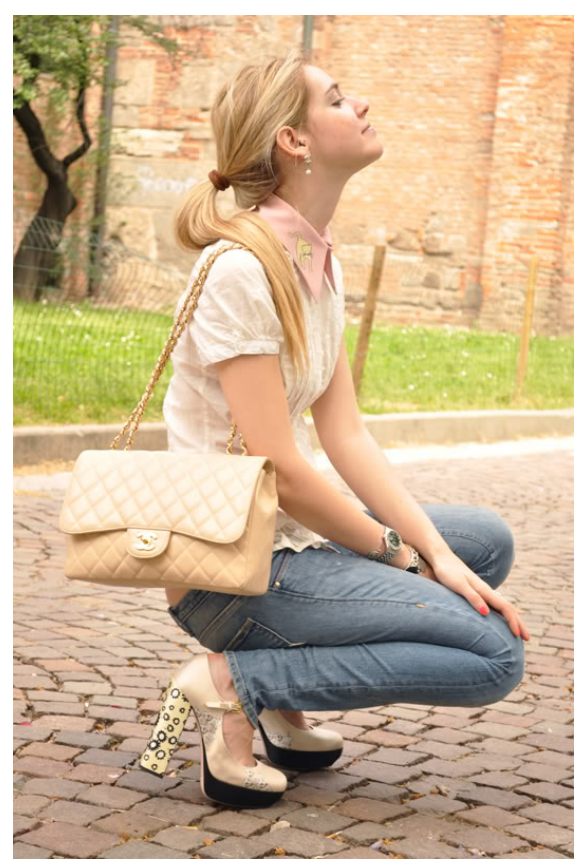

Figure 5: "Wearing Miu Miu" Ferragni in Miu Miu shoes/collar and Chanel bag
This post does several things. Importantly, the differences between this post from the year 2010 and prior posts from 2009 are striking. The photographs are better quality and Ferragni herself has changed as well. Her poses appear to be more professional and reminiscient of conventional fashion imagery and the photo quality and lighting is better than previously discussed posts. She is the only one in these photos and the playful nature of previous posts is slightly less present, although still detectable at times.

A discerning reader would notice that her confidence in herself as a player within the field of fashion has increased.

Ferragni appears to be marketing herself differently, emphasizing the outfit she has curated and a particular brand, even in the title, rather than events in her life. The outfit itself is more high-end 
than in previous posts as well; she mixes a Chanel bag and earrings and a Miu Miu collar and shoes with more mass-produced fashion, like a Zara shirt. This may be an indication of her rising economic capital, but still does show a desire to connect with her readers on some level by including some more affordable outfit options. She mentions that she would like to own the whole collection, but could only buy two items. Presumably, this is an indication to readers that she does not have the required economic capital to purchase more than she did. Her discussion of the latest Miu Miu collection proves to readers that she is up-to-date with current trends and runway collections, emphasizing her cultural capital and distinction within the field of fashion. Her deliberation on the pieces as well as her trouble styling the collar provides readers with proof that she is a real person that is not always perfectly fashion-savvy; she too has styling troubles at times. This feeds back into the perpetuation of an authentic image of herself on her blog, drawing readers in with the promise of real-life fashion. Additionally, the photos are set in a public place, which, as Pham ("I Click and Post and Breathe") discusses, "is a deliberate aesthetic counterstrategy that locates authentic style in the everyday social life of ordinary people rather than in the tightly guarded institutions and norms of luxury fashion" (236). Importantly, Ferragni is allowing readers to feel as though her own style is achievable for the average middle-class reader through this post.

\section{"My First Day of Paris Fashion Week" (4 March 2011)}

This post is written by Ferragni herself and is an update on her time thus far in Paris. It shows her outfit choice for her first day of Paris Fashion Week. Much of the post is dedicated to talking about her shoes, which are "one of the new models [she] designed for [her] shoe brand" and she tells readers about how she is proud of them (Ferragni). She mentions that photographers had been asking her what brand they are. There are eleven photos included of her outfit for this day. 
They are high quality photographs and appear to be taken by someone else on the streets of Paris (see Figure 6). In one of the photos, there is a woman in the background with a camera taking her

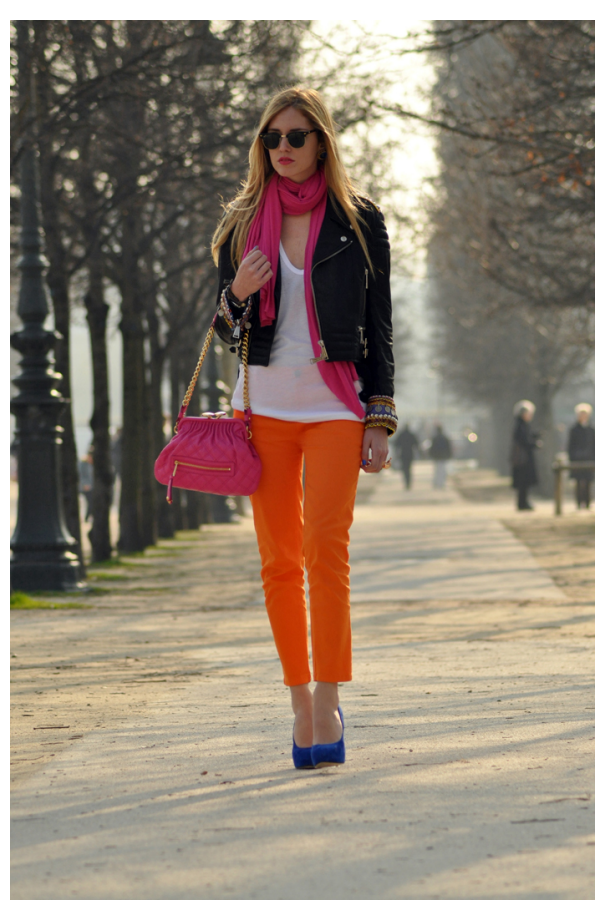

Figure 6: "My First Day of Paris Fashion Week" Ferragni walking the streets of Paris during Fashion Week 2011 photo (see Figure 7). The pictures are focused on her outfit and her poses are much more calculated and elegant. This post also includes photos of the models on the runway from the Barbara Bui fashion show that she attended that day. She talks a bit about the pieces on display at that show and then moves on to speak about the Zadig and Voltaire presentation that she attended. Some photos are included of the Zadig and Voltaire showroom and Ferragni discusses her favourite pieces. She concludes by asking her readers what they think

of the outfit, her shoes, the collections she saw in Paris, and then she lists the brands that she was wearing at the end of

the post. All text is included in both English and Italian.

Perhaps what is most blatant in this post is the mention of her new, self-titled line of shoes. This post is a blatant and public display of Ferragni's success, both on her blog and on herself as a live model for the shoes as she attended shows at Paris Fashion Week. This marks the first time in my Analysis that Ferragni is marketing herself so blatantly to her readers, demonstrating confidence in her success and in the future of her new brand. The shoes are linked for purchase in her

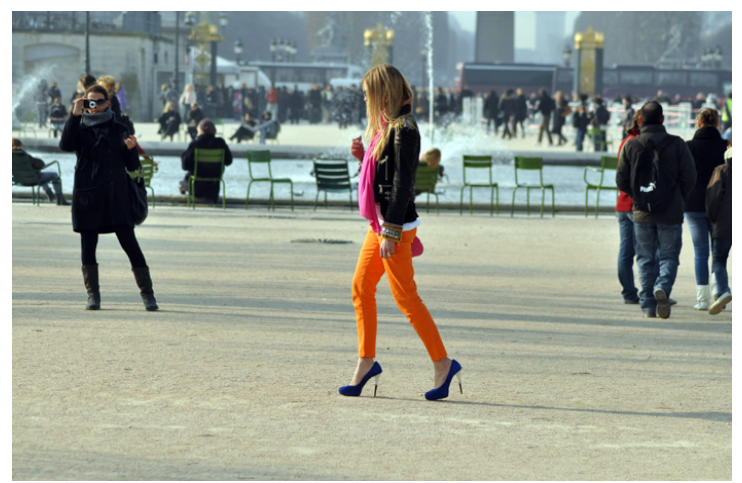

Figure 7: "My First Day of Paris Fashion Week" Ferragni wearing her own shoe collection being photographed in Paris 
outfit details at the bottom of the page. Interestingly, the ring she is wearing in some of the photos is also linked, but no other outfit details are. This is also the first indication in my Analysis of some sort of brand or retailer collaboration that Ferragni engages with, which she does not explicitly discuss in the post. Importantly, Ferragni appears to be less transparent about her own personal style choices with her readers than she previously had been, drawing forth questions of true authenticity. In addition, her outfit choices still incorporate some massproduced fashion items, but as a whole are becoming increasingly high end. Perhaps the increasingly unattainable nature of her outfits signifies a shift for Ferragni in terms of reader perception; it does not seem to matter as much to her whether or not readers believe her to be relatable to the average person. Instead, this post works to further establish Ferragni's status in the industry and the field of fashion as a whole. She discusses her time at Paris Fashion Week and gives readers a glimpse into one of the shows she was invited to, revealing her intimate ties to industry. While simultaneously providing readers limited access to an exclusive fashion event and showroom, Ferragni is establishing her own status in the field by flaunting her own invitation and access to it, echoing research previously discussed by Entwistle and Rocamora. They suggest that visibility at these events equates to power within the fashion industry, therefore Ferragni is legitimating her own position of power within the field by making herself so visible within it (743). Again, she works to display her own symbolic capital in this post in both cultural and social forms. She has the social capital to be invited to these events and photographed by others at the events as well as the cultural capital to be able to discern the value of the pieces on display. This post works to establish her success in the industry and increase reader respect of her opinion. While all this is true, she maintains a connection to her readers by asking opinions of her outfits and the collections that she showed them, fostering a feeling of 
closeness and relatability for readers even in the face of unachievable institutional access to the field.

\section{"Electric Blue Jeans + Cream Sweater" (26 October 2011)}

This is a post that appears to be about a particular outfit that Ferragni wore, as she says, "here [sic] the look I wore yesterday" (Ferragni). It is written by Ferragni and text is included in both

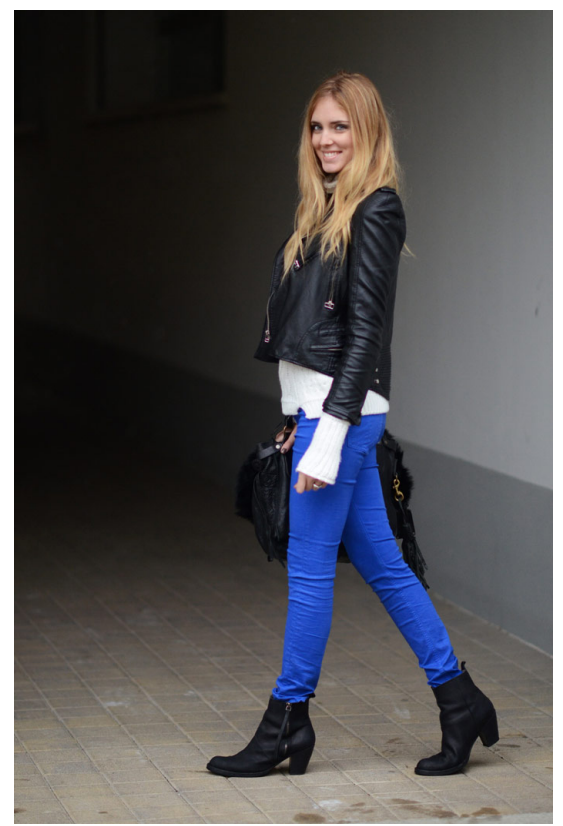

Figure 8: "Electric Blue Jeans + Cream Sweater"
English and Italian. She tells readers that, "at the end of the post, with the brands I was wearing, you can also find a new Fashiolista widget, the lists: thanks to these you'll be able to purchase online all the items I wear (or find similar ones when these ones are not available)" (Ferragni). Fourteen photos are included in the post, which are professional quality. The photos focus on specific aspects of her outfit and her poses aid in this goal (see Figure 8). The setting looks as though it could be at someone's house or a public place somewhere. At the bottom of the post where outfit details are listed, she lists some items

followed by, "thanks to.." and some items not followed by anything. For example, she lists, "Acne Pistol boots thanks to blackwhitedenim.com" as compared to "Ralph Lauren Biker Bag," suggesting that these items that include a thank you may have been gifted to her (Ferragni).

First and foremost, Ferragni's mention of the "Fashiolista widget" links her blog directly to the promotion of fashion consumption (Ferragni). The widget allows readers to shop Ferragni’s looks with just a click and also allows Ferragni to make commission off the ACNE PISTOL BOOTS thanks to blackwhitedenim.com RAG\&BONE ELECTRIC BLUE JEANS ZARA CREAM SWEATER

Figure 9: "Electric Blue Jeans + Cream Sweater" Indication of gifted merchandise for Ferragni number of clicks an item receives. This is the first post in my Analysis that openly brings up the 
idea of consumption and links Ferragni directly to brand collaboration and mutually beneficial relationships between her and the brands that she features. The introduction of the Fashiolista widget in this post acts as a symbol for Ferragni's continued accumulation of both economic and symbolic capital through the blog medium, indicating her continued success in the field. Readers also catch a glimpse of Ferragni's social capital when she starts mentioning "thanks to..." in her outfit details (see Figure 9) as she is being gifted merchandise from big companies to feature on her blog.

\section{"Show Your Potential" (24 May 2012)}

This post is in collaboration with American Express and describes her role as a "potentialist". This post is written by Ferragni and photos are taken by someone else. The post acts as a history of The Blonde Salad blog up until this point, discussing her decision to start her blog and the way she was able to turn it into her job. All information is relayed in English and Italian. She tells readers that, "potentialists are those people who made a change in their lives, or those who made their hobbies and passions become their jobs" (Ferragni). She tells readers that it began on October 12, 2009, and links her first blog post. At the time, there were only a few personal style blogs in Italy and she began updating hers every day almost immediately. She tells readers that after four months of having the blog, she received her first job proposal from Benetton. By February 2010, Ferragni tells readers that everyone at Milan Fashion Week was buzzing about the "fashion blogger phenomenon". People wrote articles about her, she was interviewed for the Italian news, and "was a guest with Mischa Barton at Chiambretti night" (Ferragni). She tells readers that she got a proposal from an Italian weekly magazine, $A$, which she still wrote for in the fashion section at the time. In this post she mentions that at that date, The Blonde Salad has around 110000 visits per day, 8.5 million page views per month, and around 730000 unique 
visitors each month from 180 countries (Ferragni). She also tells readers that she has been offered many well-paying jobs, but has often declined them because she felt that they were not the right jobs for her. She tells readers, "I have always chosen collaboration with brands I love and that I find similar to my taste: I would never wear something that I don't like on the blog. All

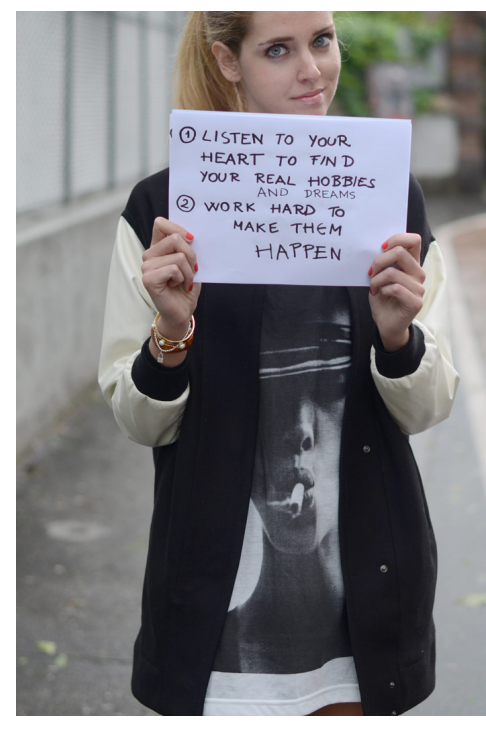

Figure 10: "Show Your Potential" Ferragni gives her readers life tips my collaborations and jobs are declared: the blog became in these years a real job for me, and I've never hidden it to my followers, it's one of my biggest satisfactions" (Ferragni).

She tells readers that in April and March of 2010, she started working on her personal shoe line called 'Chiara Ferragni,' mentioning that the line grows every season and is sold at many different retail outlets. She says that, "from that moment so many collaborations, projects, and travels arrived: I always try to keep an updated list of my experiences in the ABOUT section of the blog"

(Ferragni). In 2011, she decided to start the TBS Crew, the Blonde Salad team. She tells readers that she is "the only editor of the blog and [she's] the only one using all the social networks, but [she] could never do all these things [she does] if it wasn't for them @)" (Ferragni). She then thanks her followers and mentions how glad she is that she started the blog. The rest of the post consists of some "life tips" that Ferragni has for her readers. They are expressed through pictures of Ferragni holding hand written signs with the tips on them (see Figure 10). The photographs are followed by short text paragraphs elaborating on the tips. All text is provided in English and Italian. Her outfit remains a focus in the pictures and they are good quality. There are six photos included in the post in total. Sometimes her face is cut off so that the only focus is the outfit she's wearing and the tips she's providing. She tells her readers to follow their instincts and to 
not focus too much on negativity; rather, they should focus on passions and on doing what they love. She concludes by saying, "I hope I was able to steal a smile from your face with this post. You're one of my main strengt [sic] and I though [sic] it was the right time to try to give you some more energy back as well. If you need any advice I'm here" (Ferragni). At the end of the post she includes her outfit details.

This is the first post included in my Analysis that is open and entirely sponsored by a company, in this case, American Express. Ferragni tells her readers that the post is a collaboration, indicating that she was paid or sponsored to create it. Interestingly enough, American Express is not a company that is directly associated with the fashion industry, implying that Ferragni has gained significant influence and social capital in other fields as a result of her success in the field of fashion. This post, unsurprisingly, acts as yet another display of both economic and symbolic capital. Ferragni is open in this post about her blog being her job and she mentions numerous job opportunities (collaborations) that she has been offered over the years. In this way, while being open to readers about her successes, Ferragni is also working continuously to further her status in the field of fashion, in this case through a display of economic, social, and cultural capital. She has gained significant economic capital through these collaborations, but has also gained cultural and social capital through her ability to exercise distinction in the industry and be recognized by big brands for it. Through this post, Ferragni is able to engage in a humble brag about the influence she has accumulated while at the same time gaining the trust of her readers.

Additionally, this post also acts as an endearment of Ferragni to readers. The post brings back the idea of authenticity to the blog and shows that Ferragni values the opinions and respect of her readers. She assures readers that she will always be very open and honest with them about 
the blog and tells them that she would never accept a job offer from a brand that she did not respect. She makes mention of her Blonde Salad Team, but she also reassures readers that she is behind all blog content. She wants readers to believe that it is still her authentic voice that they are hearing in the blog. Most evidently, the tips that she provides readers with in this post perpetuate the idea that anyone could be in her position of success if they follow their dreams and put their minds to it. This assurance and encouragement that Ferragni gives her readers through these tips obscures or hides the various forms of capital that were utilized in her own life to achieve her success. These kind tips endear her to her readers and make readers feel as though she is interested in them and genuinely cares about their success. She works to be an inspirational figure for readers in this post. At the end of the post, she further perpetuates herself as a real and relatable person by making herself appear available to readers by telling them that she is always available to provide them with advice should they need it. This post is an indication that Ferragni still wants her readers to think highly of her and that she still stands behind the authenticity of the blog.

\section{“Miami Day 3" (20 December 2013)}

This post is authored by Ferragni herself and contains very little text, focusing on the photos. Text is provided in both English and Italian. She tells readers that the post features "one of [her] favourite looks from the Alberta Ferretti 2014 spring/summer collection" (Ferragni). The photos included are very professional and depict Ferragni on a public beach (see Figure 11). At the end of the post she mentions that the photos were taken by Andrew Arthur. Her poses are confident and elegant. She wears sneakers from one of her collaborations. There are eight photos included and Ferragni does not ask readers any questions or opinions. 
This post indicates a shift within Ferragni's blog posts to include less text and focus more on the photos she is featuring. In this post, her photographer is listed with her outfit details, which is the first time that Ferragni's shift to using professional photography has been acknowledged on the blog within the scope of my Analysis, which implies that a certain level of social capital has been achieved. This post appears to indicate that Ferragni is not attempting to engage with her readers; she wears only luxury designer clothing and does not ask for readers'

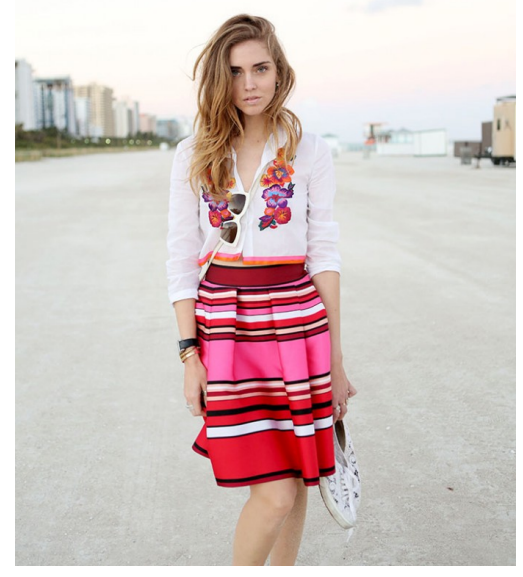

Figure 11: "Miami Day 3" opinions or inputs. Another important display of Ferragni's status in the industry is her choice of wearing shoes from one of her own designer collaboration collections. Whereas in older posts she was quite excited about wearing her own pieces, in this post it is not even acknowledged until her outfit details at the end of the post. This nonchalant attitude indicates that it has become quite a regular occurrence for Ferragni to be wearing her own collaborations, displaying her ever-increasing status within the field. Ruggerone argues that fashion "advertisements instruct us on how to pursue and enjoy particular pleasures, provide a glimpse of extraordinary lifestyles, and stimulate our desire for consumption" (356). Arguably, the visual content included in this post can be viewed as similar to fashion advertising in these ways.

\section{"California House" (16 October 2014)}

This post is written by Ferragni herself and informs readers that she has moved to Los Angeles. She mentions that she will still be going back and forth a lot between Europe and LA because her business is still in Milan. She tells readers, "I found a place in Hollywood and I'm ready to live my personal Californian dream" (Ferragni). This post contains fifteen high quality photos 


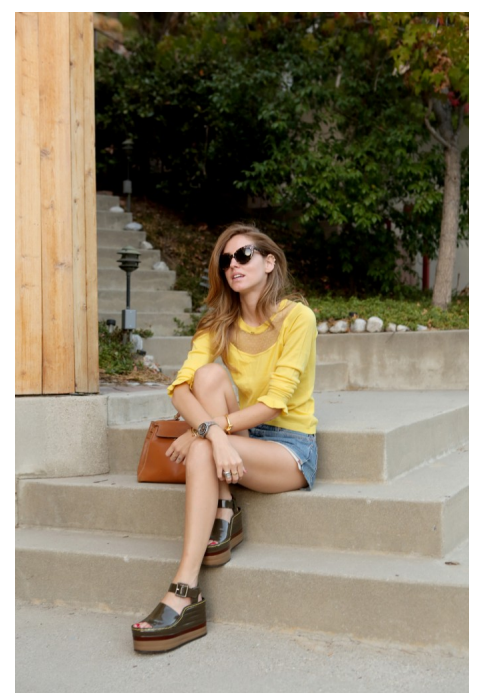

Figure 12: "California House"

displaying various aspects of one outfit. All the clothing Ferragni wears is high-end designer fashion, with brands like Celine, Valentino, Saint Laurent, and Hermes featured. This indicates that she is no longer as concerned about making her outfits accessible to the wider middle class. Instead, she is providing her readers with a display of her own status. The photos are presumably taken outside her new house in Hollywood and in many of the photos Ferragni is lounging and leaning, looking quite comfortable (see Figure 12).

This shows that she is comfortable in her own life and also emphasizes her success. Because she has been so successful globally, she has chosen to move to Los Angeles to be at the hub of her success. This move is a symbol of both her economic and symbolic capital that she has accumulated since the outset of her blog. At the end of the posts, she lists her outfit details and photographer.

\section{“Chiara Ferragni S/S 2015 Campaign” (15 January 2015)}

This is a post advertising her $\mathrm{S} / \mathrm{S} 2015$ shoe line campaign that features her in an editorial setting. The post is written by Ferragni and is not about a particular outfit. Ferragni is pictured

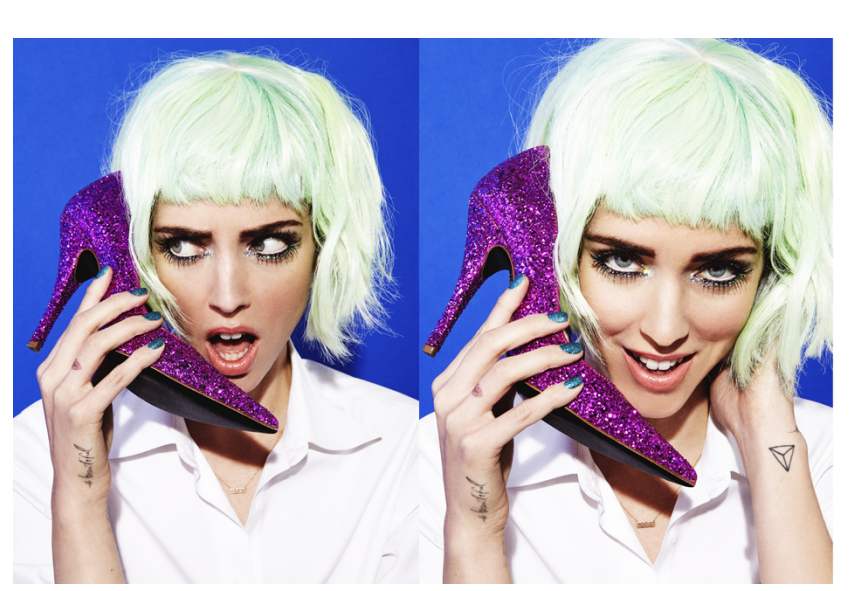

Figure 13: "Chiara Ferragni S/S 2015 Campaign" Ferragni uses a shoe she designed as a prop wearing the shoes and featuring them as props in the photos (see Figure $13 \& 14$ ). She wears several different wigs in the photos and a video is included at the end of the post showing a glance at the shooting of the campaign from backstage. Rather than listing outfit details at the end of the post, she lists 
photographer, make up artist, videographer, and music credits. Ferragni does not ask for reader opinions and this is the first time in my descriptions that a post contains only English text and no Italian. This post marks the first completely advertorial inclusion to my Analysis. The public background to the photos has been removed and the photos have become much more editorial. This may indicate, with respect to Pham's ("I Click and Post and Breathe") research, that Ferragni is implying that the type of fashion that she has grown to embody is not located in the everyday and public setting. Perhaps Ferragni is working to display her status within the field of fashion through her success yet again, and

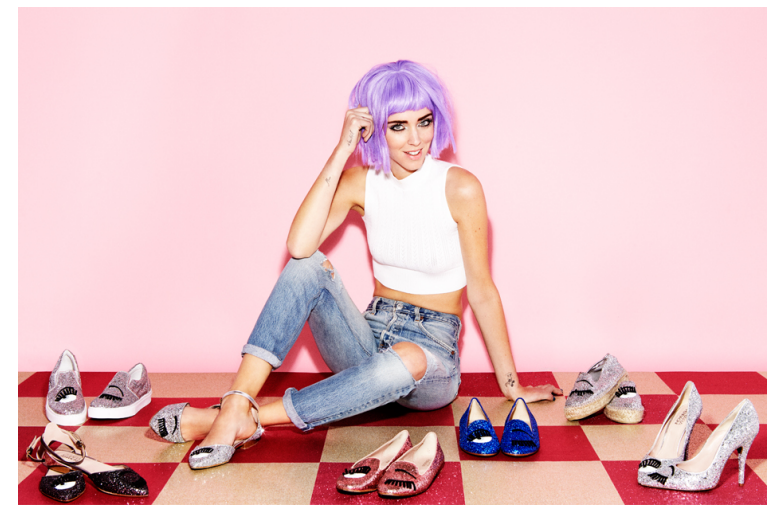

Figure 14: "Chiara Ferragni S/S 2015 Campaign" alternately locating the existence of fashion in its purest form in a conventional, editorial setting. Importantly, this post, in some ways, perpetuates and re-establishes the control of the fashion industry in traditional fashion power brokers and media forms simply by mimicking its tactics. This is a very different post than has been discussed thus far. Ferragni's own role seems to have shifted in this post as well; she has become more than her own stylist, but acts as a model in this post for her own shoe line. It appears as though this post is not concerned with perpetuating authenticity either. Ferragni's own aesthetic is inauthentic as she wears several different coloured wigs and acts as a symbol for the shift in her priorities. Contrary to her original purpose and intention, this post has nothing to do with the outfit she is wearing and focuses only on advertising her own line. In fact, her outfit details are not even included and have been replaced 
by the photographer, hair stylist, makeup artist, and etc., just as in conventional fashion magazine editorials. Importantly, this post demonstrates that Ferragni is confident enough in her status within the field of fashion to assume that her readers are interested in her for reasons other than her stylistic choices. Yet another indication of Ferragni straying from her original motives is her choice not to include an Italian translation of the post. This post can be viewed as a straying from her roots and an obscuring of her local Italian origins as well as represents a shift in the blog to a less authentic and more commercialized medium.

\section{"Sunset Lights in Paris" (6 July 2016)}

This post is authored by Ferragni and contains no text, only photos. This signifies the shift in the Blonde Salad blog in general to only include outfit photos with no text. Gone are the life updates and reader interactions that Ferragni used to post. There are seventeen professional photos in total and the photographer is listed at the end of the post. Ferragni's outfit is the focus of the pictures and her poses are reminiscent of an advertisement in a fashion magazine. Again, this makes the post appear to be more editorial than personal style blog post. She is overdressed in a public street setting in a beaded Roberto Cavalli by Peter Dundas dress and Saint Laurent shoes (see Figure 15). This is again indicative of her status in the industry; she is able to wear something that a regular consumer could not wear in a public setting without scrutiny because of her clout in the industry. She has enough capital to be able to choose

her outfits without worrying about what others may think of her.

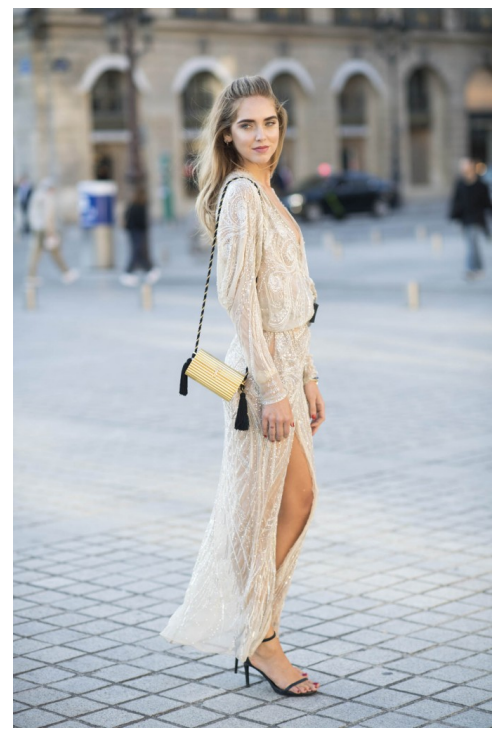

Figure 15: "Sunset Lights in Paris" In many photos the background is blurred to create further emphasis on her outfit. Outfit details are listed at the end of the post and this post again does not include an Italian translation. 


\section{“Let's Get Minimal” (8 March 2017)}

This is an outfit post authored by the TBS Crew. It is written in English only and very little text is included, telling readers only that, "Paris is always a good idea! For a short break from the shows, Chiara got minimal with a casual yet cool outfit" (TBS Crew). There are eleven professional photos included in the post. The setting appears to be the streets of Paris during Paris Fashion Week and Ferragni's outfit is the highlight of the photos. Rather than appearing at the end of the post, her outfit details are included as captions under each photo. The outfit is high

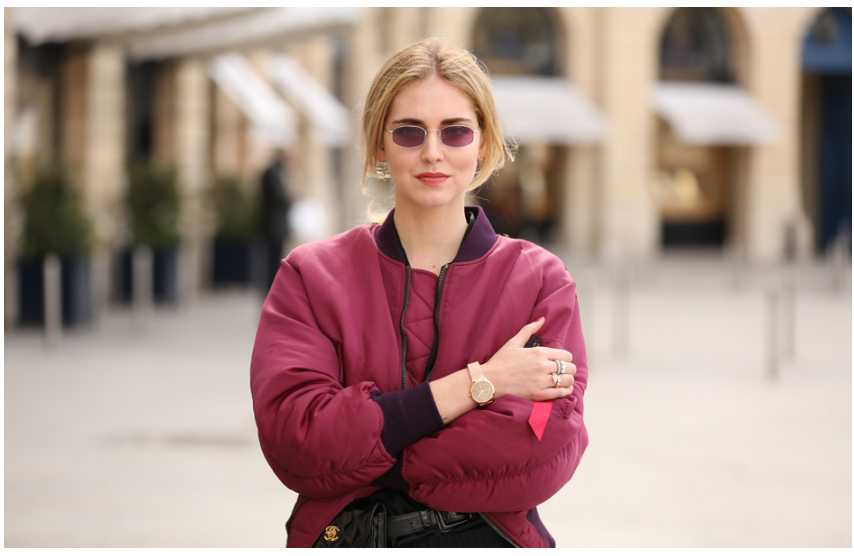

Figure 16: "Let's Get Minimal" end/luxury fashion. Ferragni's poses

highlight the clothes and show very little

personality (see Figure 16). The

photographer is listed at the end of the post.

Perhaps what is most significant

about this post is that it is the first post

included in my Analysis that is not authored by Ferragni herself. This transferrance of authorship is present in many of the blog's most recent posts and signifies a distancing of Ferragni from the blog. This shift may indicate that Ferragni is less interested in the blog as a personal style blog and is rather focused on furthering The Blonde Salad as a brand. Her team is able to maintain the blog for her and this post is the epitome of the blog's transformation from personal style blog to corporate brand blog and online retailer. The outfit she is wearing is high-end and inaccessible to most readers. Where readers used to see bits of Ferragni's personality in her posts, this post displays Ferragni as a blank canvas, emphasizing her role as a model for the clothing she is wearing. Although this post still features Ferragni, readers see more of a static image of the blogger than an actual person that they can relate to. This post again emphasizes her status within 
the industry through her attendance at Paris Fashion Week and her visibility at the shows there. This post works to emphasize Ferragni's peak capital as well as to perpetuate the accumulation of further capital (economic, social, and cultural) for the future.

\section{Concluding Case Study Discussion: The Blonde Salad Blog Progression}

As evidenced in the preceding work, the changes in Ferragni's blog take several different forms. Perhaps one of the most glaring transformations is the change in her textual content from the beginning of the blog to its current state. When she first started creating posts for the Blonde Salad blog, large blocks of text were included that worked to inform readers about Ferragni's day-to-day activities and personal anecdotes. Within posts from her first few years of blogging, readers were really able to catch a glimpse of who Ferragni was as a person through a more personal form of sharing; she included updates on some aspects of her life, textual description of events and activities that she did with her friends, and travel experiences. In a way, these textual descriptions allowed readers to feel close to Ferragni and added a personal touch to the blog. As the years progressed and the Blonde Salad blog became more and more recognized within the field, the textual content included in the posts continued to decline in focus for Ferragni. As previously discussed, the amount of text included with each post goes down as the reader gets into more recent years. Today, Ferragni's posts contain very minimal and limited textual content and are often not even authored by Ferragni herself. This means that readers experience less of Ferragni's own voice and the blog itself becomes less personal and more editorial, echoing the trends once associated with traditional fashion media, such as magazines and advertisements. This change largely indicates a distancing of Ferragni from the blog; it has become less important to her as a personal expression of her own lifestyle and has shifted to become a brand in and of itself. The intimate aspect of the blog, which is a characteristic and important aspect of 
any personal style blog, has essentially disappeared, suggesting the commercialization of what was once private.

Perhaps the most drastic evidence suggesting this commercialization is the shift that the blog undergoes to only include text in English rather than in both English and Italian. Ferragni's former inclusion of Italian text on her blog located her as an Italian resident that started a blog for means of personal expression to both her own community and the World Wide Web community at large. The inclusion of both languages made Ferragni more real and authentic for her readers because it implied that the blog was not created only to have mass readership; it appeared to be a true expression of who Ferragni was. The shift to include only English text content indicates a commercialization of The Blonde Salad blog specifically for mass audiences based on the idea that the hegemonic and most universally accepted language across the world is English. Overall, changes in text content across the span of the blog's lifetime point toward a depersonalization of blog content and a shift in focus for Ferragni's blogging career.

Visual differentiations between early and later blog posts on The Blonde Salad blog are also important for analysis. The progression in visual imagery that is included in Ferragni's posts on the blog over the years of its existence is evidenced through changes in photograph quality, photographer, outfit choices, and choice of poses. Ruggerone suggests that fashion images are, in some ways, hypertextual because they are cultural objects themselves that seek to represent other cultural objects (354). Further, she argues that, "to garments, much more than to other objects, is assigned the task of representing us, of facilitating our performance in social contexts and of revealing to others our personality and our outlook on the world" (355). In this way, then, all visual images included in posts on the Blonde Salad blog can be viewed as an expression of Ferragni's own personality to her readers because she is using the clothing that she has chosen to 
wear to do so. Importantly, though, early visual images posted on the blog display personality in a more everyday and unique way; photographs contain playful poses and are often self-portraits, which is reflected in the lower pixel quality of the earlier photographs. Importantly, though, a visual analysis of image progression in early and later posts on the blog indicates a further progression in capital for Ferragni. At first, images are amateur, often taken by Ferragni herself or by a friend. As the blog gains readership in later years, images are increasingly taken by professional photographers, indicating that Ferragni is able to afford to pay a trained photographer to take her photos. Ferragni's own poses undergo changes as well; they move from playful stances reminiscent of social media posts to very structured and elegant stances reminiscent of fashion editorial spreads.

As previously discussed, Ruggerone suggests that the role of a model in a fashion photograph is to "[interpret] a dress and [communicate] certain types of messages" through it (355). She suggests that there is a "certain sobriety and elegance" to fashion model poses, which is arguably what Ferragni increasingly embodies as posts become more recent (358). Importantly, these progressions act as visual representations of the increasing capital that Ferragni accumulates throughout her blogging career. Economic capital is chronologically increasing and is visually displayed in the quality of photographs and in the fashion content of photographs. Symbolic capital is displayed through Ferragni's progression in poses: from playful and unprofessional to more calculated and sophisticated, reminiscing conventional fashion advertisements. Ruggerone suggests that, "the central focus of fashion photography [has] shifted from the clothes to the bodies wearing them, while the tendency to attribute sexual meanings to fashion images [is] steadily increasing” (357). Arguably, Ferragni's poses in recent posts are indicative of this shift and also telling of the similarities between Ferragni's fashion blog photos 
and magazine editorial and advertorial visual images. Further, the Blonde Salad blog's shift to focus largely on photographs for visual representation rather than textual representation, as discussed above, implies confidence in the power of visual imagery to display status within the field. This further aligns with Ruggerone's idea that, “economic status, class belonging, taste, and personality are all conveyed into, and mediated by, the presentation of the dressed body" (356).

Finally, an exploration of the Blonde Salad blog's overall progress in relation to my theoretical framework is an important aspect for analysis. Bourdieu set out to explain the ways in which social practices became controlled by regularities (Maton 50). Importantly, Ferragni’s behaviour and social practices are eventually exempt from regulation by regularities on her blog because she possesses the status within her field to remain outside of these constraints. How did this exemption come to be? In relation to Bourdieu's concept of habitus, Ferragni's own perceptions of the world are, based on the limited information provided on the blog, structured and influenced by her status as a mid-high class person before the advent of her fashion blog. Ferragni's habitus was strong based on her location in Milan (a world fashion capital) as well as her natural inclination toward a body and look that conforms to conventional beauty ideals and privilege, providing her with a lot of potential within the industry. Consequently, her habitus led to her practice or her actions within the field of fashion. Because her habitus was strong, she was able to see potential for herself within the industry. Maton suggests that our position within a particular field impacts our range of choices, "but at the same time which of these choices are visible to us and which we do not see as possible are the result of our past journey" (52). Ferragni was able to see possibility in herself, therefore implying that her past journey had somehow provided her with this confidence. Additionally, Thomson mentions that players have 
limitations on what they can accomplish within a given field based on "the condition of the field they were in" (69). Ferragni mentions in her "About" section of the blog that there were very few fashion blogs on the Italian market when she started hers, indicating that the condition of the field of fashion was ready to welcome the fashion blog into the industry, which impacted her success.

Thomson explores Bourdieu's idea that "players who begin with particular forms of capital are advantaged at the outset because the field depends on, as well as produces more of, that capital" so that some players in the field are better equipped for success than others (69). Ferragni was somewhat advantaged at the outset of her blog, possessing at least some significant level of both economic and symbolic capital, as discussed in my analysis of her posts. Using this initial capital, Ferragni was able to work and leverage the system to advance her own position within the field. Ferragni was able to maintain and advertise her position within the field through the constant perpetuation of her status and capital throughout the progression of her blog, as previously discussed. Ferragni's power within the industry was, then, consistently reproduced, resulting in the accumulation of further capital for her and indicating unequal grounds for other players within the field. In this way, while at times Ferragni made it appear as though her status is achievable for the average person (see "Show Your Potential" post analysis, for example), in reality success is notably determined by the possession of capital and status. Further, as a result of the accumulation of different forms of capital that Ferragni was able to achieve, she was able to receive distinction within the field, endowing her with further cultural capital. Further, in relation to Moore's assertion that cultural products gain value within a field based on "the endorsement of these products by players with distinction," Ferragni was offered collaborations with fashion brands and was gifted merchandise because of her status of distinction (108). She, 
as an important player within the field of fashion, is able to endorse cultural and fashion objects with perceived intrinsic value on the part of consumers, increasing the item's market value and capital worth. This is what draws brands to her, allowing Ferragni to capitalize off of their influence as well. According to Rocamora ("Fields of Fashion"), the symbolic value of the object or label is changed by its association with a player with power within in the industry (349). Ferragni's consistent ability to leverage her audience of blog readers and her accumulation of capital allowed for her to exponentially obtain large amounts of capital progressively throughout the maintenance of her fashion blog. In this way, Ferragni fits in with McQuarrie et al.'s concept of the blogger as cultural capitalist; she was able to use the capital and status that she had within the industry to create a circular system of capital accumulation through which she benefitted greatly. Today, Ferragni's capital within the field of fashion continues to accumulate, endowing her with more and more power and establishing her as a key player within the industry, which is continually evidenced by her involvement in important industry events and unrelentingly increasing blog readership. 


\section{CONCLUSION}

In concluding my research, I have explored the concept of democracy in relation to the growing popularity of fashion blogging as a form of fashion media. Through my analysis of the Blonde Salad blog, I have discussed the potential for conventional power hierarchies to control and/or influence the fashion blogosphere. Where optimistic assumptions surrounding the democratizing potential of new media forms like fashion blogging have given consumers hope surrounding their own potential to have influence within the fashion industry, these optimistic ideas have also, in some ways, masked the role that traditional fashion experts play within the blogosphere. Importantly, as was evident in my Analysis of the Blonde Salad blog, bloggers that gain enough economic and symbolic capital through their blogging career actually become fashion experts themselves, often falling under the same influences as traditional forms of fashion media historically have. Overall, the pursuit of capital is a driving force within all forms of fashion media; the blogosphere is no exception.

One important thing to touch upon with regard to the Blonde Salad blog is the differences in how readers may perceive the blog vs. the reality of the blog. Although much of Ferragni's blog is very personal and does provide readers with a glimpse into her life, it is also very obscure. She does not provide any background explanation as to who she really is. Instead, Ferragni simply tells readers that after gaining popularity on other social media sites, she decided she wanted "a space for her own" (Ferragni "About"). She does not tell readers how she was able to gain followers on other sites or why she began to share content in the first place. She mentions nothing about her family and who they are or what they do. Instead, she mentions that she inherited her love of fashion from her mother, but does not mention why her mother enjoyed fashion or even whether she was part of the industry. She tells readers about her 
accomplishments, but makes no mention of the specificities that allowed her to achieve the success that she has had with her blog.

The obscure nature of the posts could be intentional or not, but there is no doubt that the lack of detail surrounding Ferragni's own beginnings obscure the various relations of power that may have influenced her success. She may have had connections in the fashion industry to begin with; she may have grown up in a very wealthy and economically privileged family; she may have had help starting her social media career; readers simply do not know the full truth.

Ferragni makes herself relatable to her readers, allowing them to trust in her as an authentic and real source for style inspiration. This makes readers feel close to Ferragni, masking any questions about the nature of her success. Ferragni's apparent transparency in her blog, particularly in early posts, perpetuates reader loyalty and respect. This illusion of authenticity works to disguise the various forms of capital that Ferragni possessed before starting the blog, creating the optimistic idea that anyone with a computer and access to the Internet can create an influential blog within the fashion industry. Further, these optimistic ideas also obscure the influences of conventional power authorities within the fashion industry on her blog content, allowing for readers to believe that Ferragni's content is entirely user-generated and separating her blog from the perceived constraints of traditional forms of fashion media.

While my research explores the democratic potential of fashion blogging within fashion media and uses the example of the Blonde Salad Blog to illustrate certain concepts, there is much more research to be done on the blogosphere as a site of resistance to hegemonic fashion norms. More in-depth textual and visual analyses of popular fashion blogs would aid in providing evidence for the influence of conventional fashion authority on the blogosphere. Primary research that engages with fashion blog authors directly using tactics like interviews would 
provide a more in-depth account of bloggers' own motivations and influences. Research that explores and compares several top-ranking fashion blogs and their readership, including blog post content and comments, would provide a more comprehensive overview the power relations at play within the fashion blogosphere as whole. Further research, both primary and secondary, on fashion blog readers and their motivations would further inform ideas surrounding readership and author-commentator interaction.

In conclusion, then, the fashion blog can act as both a space of potential for those traditionally excluded from access to the fashion industry as well as a space for the reproduction of conventional fashion norms and hierarchies. Rocamora ("Personal Fashion Blogs") argues that while the blogosphere does reproduce some of the problematic norms and power structures associated with the fashion industry, "it is also a possible space of articulation of a female voice on appearance, by and for women, a space for the expression of other images of the fashionable" (422). Pham's ("Blog Ambition") work discusses the idea that coupled with issues of capital, the Internet allows "only the most popular Web sites and blogs" to show up in web searches (9). For this reason, Pham argues that, "while the Internet may democratize communication systems, it is a democracy of popularity rather than equitability" (9). She further suggests that bloggers are able to use the blogging platform "in ways that disrupt hegemonic relations among digital and visual technologies, consumer capitalism, and racialized femininity," but that this does not necessarily indicate the existence of a more democratic media system (10). She suggests that fashion blogs are often "not external to historical systems of representation, labor, and capital. They emerge from and critically engage with these systems that continue to shape and limit individuals' everyday experiences and cultural practices in relation to fashion" (10). 
Connell argues that blogs do have important transformative potential within the fashion industry, but are mediated by "the powerful and insidious dynamics that maintain uneven regimes of power" (221). Crewe argues that although blogging is undergoing a professionalization, bloggers can nonetheless "be seen as a mechanism for redistributing fashion knowledge and democratizing fashion via open-source branding" (773). She suggests that the mechanisms involved in the fashion blogosphere "signal both disruption and disturbance to the conventional power relations that structure fashion" (777), and that although capitalist ideals still saturate the fashion blogosphere, fashion blogs may still suggest, "a flattening of fashion's longestablished hierarchies" (776). Rocamora ("Personal Fashion Blogs") argues that despite some of the conventional power hierarchies present within them, fashion blogs have the potential to aid in the establishment of a fashion market "that is not centered on a producing elite and ruled by the male gaze only but a fashion open to appropriation and interpretation" (422). Pham ("Blog Ambition") suggests that although "far from a utopian site of social, economic, political, or technological democracy, the fashion blogosphere is nevertheless a significant cultural site in which the struggle over the meanings of race, gender, sexuality, and political action happen every day" (28). Connell argues that the evidence of the transformative potential of fashion blogging "suggests that scholars should take seriously the possibility of fashion as a medium of political resistance rather than just a way of reproducing social inequalities" (222). This research has thus proven that, "the relationship between the consumer and the fashion industry is fundamentally changing," and provides a resource for the analysis of the transformative potential that fashion blogs do have within the industry (Crewe 776). As previous research on the topic suggests, despite the tendency for fashion blogs to fall victim to traditional power influences, as shown in my analysis of the Blonde Salad blog, they have also created an important site of 
resistance to hegemonic norms and values traditionally associated with the fashion industry.

Only time will tell the future of the fashion blogosphere as an exemplar of a participatory and inclusive fashion industry that openly embraces diversity. 


\section{WORKS CITED}

Alasuutari, Pertti, Luomanen, Jari, \& Peteri, Virve. "Hobbies and Vices, Book Lovers and Nerds: Discursive Management of the Digital Media Environment." Television and New Media, vol. 14 , no. 5, 2012, pp. 457-75.

Connell, Catherine. "Fashionable Resistance: Queer 'Fa(t)shion’ Blogging as Counterdiscourse.” WSQ: Women's Studies Quarterly, vol. 41, no. 1 \& 2, 2013, pp. 209-24.

Corcoran, Cate T. "Rule of the Masses: Reinventing Fashion Via Crowdsourcing." WWD, vol. 200, no. 17, 2010, n.p.

Cover, Rob. "New Media Theory: Electronic Games, Democracy and Reconfiguring the AuthorAudience Relationship." Social Semiotics, vol. 14, no. 2, 2004, pp. 173-91.

Crewe, Louise. "When Virtual and Material Worlds Collide: Democratic Fashion in the Digital Age.” Environment and Planning, vol. 45, no. 1, 2013, pp. 760-80.

Engholm, Ida; Hansen-Hansen, Erik. "The Fashion Blog as Genre: Between User-Driven Bricoloage Design and the Reproduction of Established Fashion System.” Digital Creativity, vol. 25, no. 2, 2014, pp. 140-54.

Entwistle, Joanne. The Fashioned Body: Fashion, Dress, \& Modern Social Theory. 2nd ed., Polity Press, 2015.

Entwistle, Joanne \& Rocamora, Agnes. "The Field of Fashion Materialized: A Study of London Fashion Week.” Sociology, vol. 40, no. 4, 2006, pp. 735-51.

Ferragni, Chiara. "About Us - Chiara Ferragni." TheBlondeSalad, The Blonde Salad, www.theblondesalad.com/about, Accessed 5 February 2017.

---. "After the Cinema." TheBlondeSalad, The Blonde Salad, 14 October 2009, www.theblondesalad.com/talents/chiara-ferragni/after-the-cinema. 
---. "Best of 2013." TheBlondeSalad, The Blonde Salad, 31 December 2013, www.theblondesalad.com/talents/chiara-ferragni/best-of-2013.

---. "California House.” TheBlondeSalad, The Blonde Salad, 16 October 2014, www.theblondesalad.com/talents/chiara-ferragni/california-house.

---. "Chiara Ferragni S/S 2015 Campaign.” TheBlondeSalad, The Blonde Salad, 15 January 2015, www.theblondesalad.com/talents/chiara-ferragni/chiara-ferragni-ss-2015campaign.

---. "Electric Blue Jeans + Cream Sweater." TheBlondeSalad, The Blonde Salad, 26 October 2011, www.theblondesalad.com/talents/chiara-ferragni/electric-blue-jeans-creamsweater.

---. "Here I Am!” TheBlondeSalad, The Blonde Salad, 12 October 2009, www.theblondesalad.com/talents/chiara-ferragni/here-i-am.

---. "Miami Day 3." TheBlondeSalad, The Blonde Salad, 20 December 2013, www.theblondesalad.com/talents/chiara-ferragni/miami-day-3.

---. "Milano by Night." TheBlondeSalad, The Blonde Salad, 23 October 2009, www.theblondesalad.com/talents/chiara-ferragni/milano-by-night.

---. "My First Day of Paris Fashion Week." TheBlondeSalad, The Blonde Salad, 4 March 2011, www.theblondesalad.com/talents/chiara-ferragni/my-first-day-of-paris-fashion-week.

---. "Show Your Potential.” TheBlondeSalad, The Blonde Salad, 24 May 2012, www.theblondesalad.com/talents/chiara-ferragni/show-your-potential.

---. "Sunset Lights in Paris." TheBlondeSalad, The Blonde Salad, 6 July 2016, www.theblondesalad.com/talents/chiara-ferragni/sunset-lights-in-paris. 
---. "Wearing Miu Miu.” TheBlondeSalad, The Blonde Salad, 28 May 2010, www.theblondesalad.com/talents/chiara-ferragni/wearing-miu-miu.

Fink, Marty \& Miller, Quinn. “Trans Media Moments: Tumblr, 2011-2013.” Television and New Media, vol. 15, no. 7, 2014, pp. 611-26.

Friedland, Lewis A. "Electronic Democracy and the New Citizenship." Media, Culture, and Society, vol. 18, no. 1, 1996, pp. 185-212.

Grenfell, Michael. "Introduction to Part II." Pierre Bourdieu: Key Concepts, edited by Michael Grenfell, Acumen Publishing Limited, 2008, pp. 43-47.

Hebdige, Dick. "Chapter One - From Culture to Hegemony." Subculture: The Meaning of Style, Routledge, 2012, pp. 5-19.

Indvik, Lauren. "The 20 Most Influential Personal Style Bloggers: 2016 Edition.” Fashionista, 14 March 2016, www.fashionista.com/2016/03/style-bloggers-2016, accessed 20 February 2017.

Jacobs, Alexandra. "Fashion Democracy: Annals of Style." The New Yorker, 29 March 2010, np. Lenhart, Amanda \& Fox, Susannah. "Bloggers: A Portrait of the Internet's New Storytellers." PEW Internet and American Life Project Report (2006). Web. 18 April 2016. http://www.pewinternet.org/

Loader, Brian D. \& Mercea, Dan. "Introduction: Networking Democracy? Social Media Innovations and Participatory Politics.” Information, Communication, \& Society, vol. 14, no. 6,2011 , pp. 757-69.

Maton, Karl. "Chapter 3 - Habitus." Pierre Bourdieu: Key Concepts, edited by Michael Grenfell, Acumen Publishing Limited, 2008, pp. 49-66. 
Matthews, Rachel. "Contemporary Fashion Tastemakers: Starting Conversations that Matter." Catwalk: The Journal of Fashion, Beauty, and Style, vol. 4, no. 1, 2015, pp. 51-70. McQuarrie, Edward; Miller, Jessica; Phillips, Barbara. "The Megaphone Effect: Taste and Audience in Fashion Blogging." Journal of Consumer Research, vol. 40, no. 1, 2013, pp. $136-58$.

Meyers, Erin. “'Blogs Give Regular People the Chance to Talk Back': Rethinking 'Professional' Media Hierarchies in New Media." New Media \& Society, vol. 14, no. 6, 2012, pp. $1022-$ 38.

Moore, Robert. "Chapter 6 - Capital." Pierre Bourdieu: Key Concepts, edited by Michael Grenfell, Acumen Publishing Limited, 2008, pp. 101-18.

Onion, Rebecca. "The Awful Emptiness of 'Relatable'.” Slate, 11 April 2014, www.slate.com/blogs/lexicon_valley/2014/04/11/relatable_the_adjective_is_everywhere _in_high_scchool_and_college_discussions, accessed 21 April 2017.

Pham, Minh-Ha. "Archival Intimacies: Participatory Media and the Fashion Histories of US Women of Colour." Fashion, Style, and Popular Culture, vol. 2, no. 1, 2014, pp. 107-22.

--- "Blog Ambition: Fashion, Feelings, and the Political Economy of the Digital Raced Body." Camera Obscura, vol. 26, no. 1, 2011, pp. 1-37.

---. “I Click and Post and Breathe, Waiting for Others to See What I See': On \#FeministSelfies, Outfit Photos, and Networked Vanity." Fashion Theory: The Journal of Dress, Body, and Culture, vol. 19, no. 2, 2015, pp. 221-41.

---. "The Right to Fashion in the Age of Terrorism." Signs, vol. 36, no. 2, 2011, pp. 385-410. 
Pihl, Christofer \& Sandström, Christian. "Value Creation and Appropriation in Social Media The Case of Fashion Bloggers in Sweden.” International Journal of Technology Management, vol. 61, no. 3 \& 4, 2013, pp. 309-23.

Pratchett, Lawrence. "New Fashions in Public Participation: Towards Greater Democracy?" Parliamentary Affairs, vol. 52, no. 4, 1999, pp. 616-33.

Rocamora, Agnès. "Fields of Fashion: Critical Insight into Bourdieu's Sociology of Culture.” Journal of Consumer Culture, vol. 2, no. 3, 2002, pp. 341-62.

---. "Pierre Bourdieu: The Field of Fashion.” Thinking Through Fashion. Ed. Agnès Rocamora, Anneke Smelik. London; New York: I.B. Tauris \& Co. Ltd, 2016. 233-50. Print.

---. "Hypertextuality and Remediation in the Fashion Media." Journalism Practice, vol. 6, no. 1, 2012, pp. 92-106.

---. "Personal Fashion Blogs: Screens and Mirrors in Digital Self-Portraits." Fashion Theory, vol. 15, no. 4, 2011, pp. 407-24.

Ruggerone, Lucia. “The Simulated (Fictitious) Body: The Production of Women's Images in Fashion Photography." Poetics, vol. 34, no. 1, 2006, pp. 354-69.

Scaraboto, Daiane; Fischer, Eileen. "Frustrated Fatshionistas." Journal of Consumer Research, vol. 39, no. 6, 2013, pp. 1234-57.

Sedeke, Kristina \& Arora, Payal. "Top Ranking Fashion Blogs and Their Role in the Current Fashion Industry." First Monday, vol. 18, no. 8, 2013, np.

TBS Crew. “Let’s Get Minimal.” TheBlondeSalad, The Blonde Salad, 8 March 2017, www.theblondesalad.com/talents/chiara-ferragni/lets-get-minimal.

Thomson, Patricia. "Chapter 4 - Field.” Pierre Bourdieu: Key Concepts, edited by Michael Grenfell, Acumen Publishing Limited, 2008, pp. 67-81. 
Vatikiotis, Pantelis. "New Media, Democracy, Participation and the Political." Interactions:

Studies in Communication \& Culture, vol. 5, no. 3, 2014, pp. 292-307. 